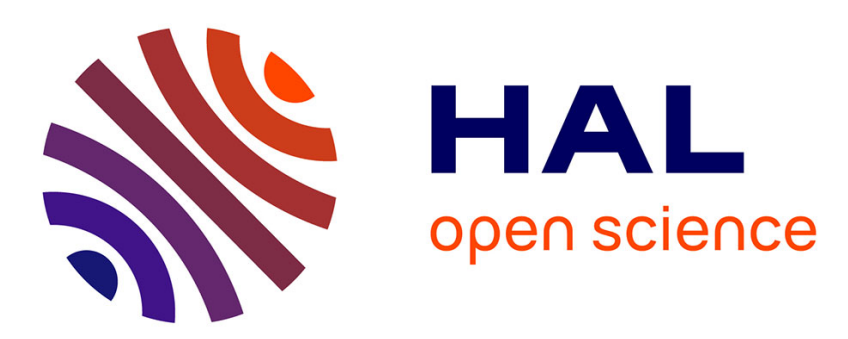

\title{
Tailoring the fluid flow distribution in a parallel mini-channel heat sink under multiple-peak heat flux
}

Yijun Li, Stéphane Roux, Cathy Castelain, Lingai Luo, Yilin Fan

\section{To cite this version:}

Yijun Li, Stéphane Roux, Cathy Castelain, Lingai Luo, Yilin Fan. Tailoring the fluid flow distribution in a parallel mini-channel heat sink under multiple-peak heat flux. Thermal Science and Engineering Progress, 2022, 29, pp.101182. 10.1016/j.tsep.2021.101182 . hal-03524834

\section{HAL Id: hal-03524834 \\ https://hal.science/hal-03524834}

Submitted on 13 Jan 2022

HAL is a multi-disciplinary open access archive for the deposit and dissemination of scientific research documents, whether they are published or not. The documents may come from teaching and research institutions in France or abroad, or from public or private research centers.
L'archive ouverte pluridisciplinaire HAL, est destinée au dépôt et à la diffusion de documents scientifiques de niveau recherche, publiés ou non, émanant des établissements d'enseignement et de recherche français ou étrangers, des laboratoires publics ou privés. 


\title{
Tailoring the fluid flow distribution in a parallel mini-channel heat sink under multiple-peak heat flux
}

\author{
Yijun LI, Stéphane ROUX, Cathy CASTELAIN, Lingai LUO, Yilin FAN* \\ Université de Nantes, CNRS, Laboratoire de thermique et énergie de Nantes, LTeN, \\ UMR6607, F-44000 Nantes, France
}

\begin{abstract}
:
Parallel micro/mini-channel heat sinks are widely used for the efficient cooling of electronic devices to avoid functional damage and lifetime shortening due to overheating. This study addresses the optimization of fluid flow distribution in parallel mini-channel heat sinks subjected to a non-uniform multiple-peak heat flux to eliminate the temperature hotspots. A 3D heat sink comprising of 16 parallel straight mini-channels is used as a model for study, each mini-channel having the dimension of $1 \mathrm{~mm}$ in width, $2 \mathrm{~mm}$ in height and $34 \mathrm{~mm}$ in length. In particular, an original optimization algorithm is developed to adjust the inlets of these mini-channels according to the temperature distribution on the heating base surface. The fluid flow distribution is thereby tailored, leading to the reduced peak temperature on the heating surface. The effectiveness and robustness of the optimization algorithm are tested and discussed.
\end{abstract}

Results obtained show that the maximum temperature can be reduced by $10 \mathrm{~K}$ and $7 \mathrm{~K}$ for two-peak and five-peak heat flux cases, respectively, by using the proposed optimization method. The heat sink configuration with optimized channel inlets could always provide smaller thermal resistance than that of the equal channel inlet configuration under different average heat flux or total mass flow-rate conditions. At the same pressure drop, tailoring the flow distribution of the cooling fluid is more effective in reducing the thermal resistance than simply increasing the mass flow rate of the cooling liquid. This optimization method could also be generalized as an efficient thermal management technology for electronic cooling.

Keywords: Mini-channel heat sink; Fluid flow distribution; Temperature hot spots; Multiple-peak heat flux; Thermal management; Optimization 


\section{Introduction}

Human society has made remarkable progress in the past few decades because of the fast development of computing and information technologies. The demand for smaller, faster, more powerful electronic devices (e.g., computer chips, laser diodes, graphic chips, etc.) provokes an ever-increasing heat flux generated [1]. The higher junction (chip) temperatures due to the increasing power density not only greatly deteriorate the performance of electronic devices but also reduce their lifetime [2], such that for every $10 \mathrm{~K}$ rise in the junction temperature, the device failure rate doubles [3]. Therefore, it is of essential importance to maintain the junction temperatures at a low level (e.g., less than $359 \mathrm{~K}$ for the processor: Intel ${ }^{\circledR}$ Core $^{\mathrm{TM}} \mathrm{i} 9-10980 \mathrm{XE}$ [4]) by more innovative and efficient thermal management/electronics cooling [5].

Among various electronic cooling techniques, miniaturized heat sinks are widely used because of their high heat dissipation ability and easy integration with the chips [6]. Usually, the heat sink is attached to the heat-generating surface of an electronic component, with one or two thin thermal interface material (TIM) layers in between ensuring good thermal contact [7]. The flowing of a coolant (air, liquid) inside the structure of the heat sink (e.g., parallel channels; pin fin; etc.) could efficiently remove the generated heat via the convection heat transfer. Especially, liquid cooling with the higher thermal transfer efficiency than air cooling is used in high-power modules [8].

Among various structures of heat sinks for electronic cooling, the parallel straight $\mathrm{micro} / \mathrm{mini}$ channel configuration is the most widely used one because of its simple geometry, high cooling performance, cost-effective fabrication and easy implementation [9]. It usually comprises single inlet and outlet ports, inlet/outlet manifolds and a multitude of micro/minichannels in the middle. Due to their geometric specificity, the presence of the coolant flow maldistribution may result in the thermal performance deterioration of the heat sink and the formation of localized temperature hot spots in the electronic device [10]. Therefore, one important issue that attracts great attention is how to properly deliver and distribute the cooling fluid across the parallel micro/mini channels in order to ensure the optimal cooling performance. Plenty of researches have been devoted to achieving the uniform flow distribution in parallel channel heat sinks under the assumption of a uniform heat flux as their heat source. These researches can mainly be classified into three categories: (1) arrangement of heat sink inlet/outlet positions or the injecting angle; (2) design and structuration of the manifolds (headers); and (3) shape modification of the parallel channels.

Kumar and Singh [10] numerically tested the effect of flow inlet angle between the inlet port and the parallel channels (theta $=90^{\circ}, 105^{\circ}$, and $120^{\circ}$ ) on the flow distribution non-uniformity of water and the thermal performance of a mini channel heat sink. It was found that the inlet angle of $105^{\circ}$ provided the best flow uniformity and the best thermal performance under the uniform heating condition. Manikanda Kumaran et al. [11] experimentally and numerically studied the locations of inlet/outlet (U, C, V, S and D type 
as shown in Fig. 1) on the water distribution non-uniformity. Their results showed that the main reasons for non-uniform flow distribution were the presence of secondary flow, the flow separation and the re-circulation. Among the tested heat sink types, the C-type arrangement exhibited the best flow distribution uniformity whereas the $\mathrm{V}$-type heat sink had the poorest (cf. arrangements schematized in Fig. 1). Similarly, the effect of inlet/outlet arrangement was numerically studied by Chein and Chen [12]. They found that the fluid flow (water) velocity distribution is less uniform for the heat sinks with coplanar inlet/outlet tube and parallel channels (I, N, D, and S type in Fig. 1) than those with vertical fluid supply and collection ( $U$ and $V$ types; i.e. inlet/outlet tubes are perpendicular to the parallel channels). Kumar and Singh [13] investigated different types of flow arrangement in various water-cooled heat sinks, and their numerical results showed that I-type flow arrangement could provide better thermal performance for uniform heating than D-type heat sink having the more uniform flow distribution.
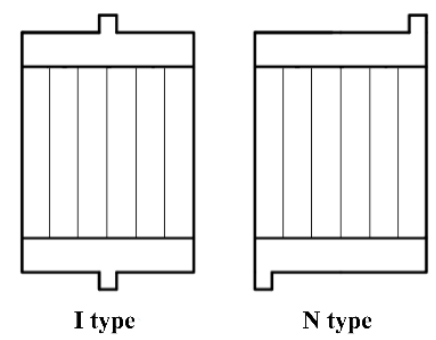

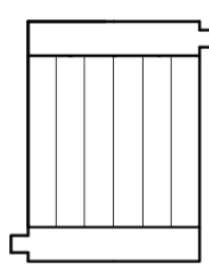

S type

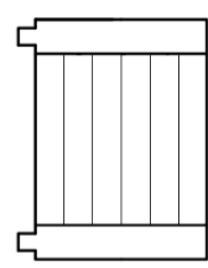

D type

Inlet/outlet are coplanar to the channels

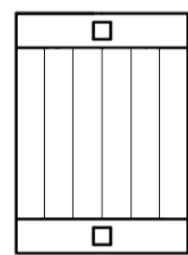

U type

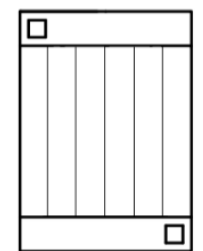

V type

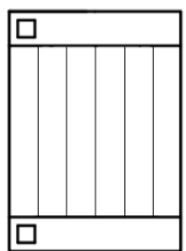

C type

Inlet/outlet are perpendicular to the channels

Figure 1. Different arrangements of global inlet-outlet position for parallel straight channel heat sinks

Manikanda Kumaran et al. [11] also tested different header shapes (rectangular, triangular and trapezoidal) and header sizes. Their results showed that the triangular inlet header and the trapezoidal outlet header provided better flow uniformity than others. Many other novel header designs [11,14-17] have also been proposed and tested, as summarized in the review paper by Ghani et al. [18]. Different from the studies on the inlet header shapes, Song et al. [19] proposed to add a staggered pin-fin array in the inlet header of the watercooled heat sink. The influences of different pin-fin arrangements in trapezoidal or rectangular inlet header on the flow distribution uniformity among the mini-channels were numerically assessed. Liu and $\mathrm{Yu}$ [20] proposed a non-uniform sized mini inlet baffle to intentionally control the water flow rate in the mini-channels. Their numerical results showed that both the flow distribution uniformity and the temperature uniformity at the 
heating base wall could be improved by using the appropriate baffle. Nevertheless, no optimization procedure has been proposed to determine the best baffle geometry.

The geometry of the heat sink channel is also considered as a design parameter in many studies. Dhahad et al. [21] showed a decreased flow non-uniformity with decreasing header/channel area ratio. Ge et al. [22] proposed a multi-objective genetic algorithm (MOGA) and particle swarm optimization (MOPSO) to optimize the variables describing the cross-section shape of mini-channels (water as working fluid). Their results showed that the pumping power could be effectively reduced without significantly increasing the thermal resistance by modifying the rectangular cross-section shape to a curvy boundary shape. Mu et al. [23] proposed parallel channel water-cooled heat sinks with variable channel height. Their results showed that the temperature non-uniformity $\left(T_{\max }-T_{\min }\right)$ of the heating surface could be reduced from $4.7 \mathrm{~K}$ to $0.97 \mathrm{~K}$ and the thermal resistance be decreased from $0.03 \mathrm{~W} \cdot \mathrm{K}^{-1}$ to $0.028 \mathrm{~W} \cdot \mathrm{K}^{-1}$ by replacing the conventional channels with the variable height channels. Hao et al. [24] numerically investigated the effect of geometry parameters (number of channels, channel width and channel length) of the water-cooled heat sink. Optimal values of channel number, channel width, and length were determined for both flow distribution uniformity and maximum temperature reduction, using the orthogonal experiment design method. The effects of different channel dimensions (parameters) on the reduction of thermal resistance were numerically examined by Mitra and Ghosh [25], and the optimum dimensions of the water cooled mini-channel heat sink modelled as fins on a substrate have been determined.

All the above-mentioned studies aimed at achieving uniform flow distribution under the assumption of uniform heat flux at the base wall of the heat sink. But in reality, the heat flux profile generated by the electronic devices is not uniform, instead, it presents multiple peaks $[26,27]$. This multiple-peak heat flux could either be due to the non-uniform heat generation of a single chip (e.g., multi-core microprocessors) [28], or due to the existence of multiple chips on the module (MCM) [29]. Under these circumstances, the intentional flow non-uniform distribution may be a better option to be adapted to decrease the local maximum temperature, as pointed out by Kumar and Singh [13]. This is actually in line with some observations reported in the literature [30-32] in that the optimal flow distribution is usually not uniform but obeys certain trends subjected to a defined optimization objective and constraints. In this regard, Kumar and Singh [13] indicated that the flow arrangement and the actual flow distribution should fit the heat flux shape to achieve a better thermal performance, i.e., lower maximum temperature and thermal resistance. Yet, no optimization method has been developed so far to determine the optimal flow distribution profile.

The above literature survey indicates that systematic and quantitative studies addressing flow and temperature distribution characteristics in the parallel micro/mini channels heat sink under non-uniform and multiple-peak heat flux conditions are still lacking. In particular, the relation between the optimal flow distribution of cooling fluid and the 
heat flux on the heating surface is unclear. Moreover, investigations on the development of effective methods to determine and realize the most adapted flow distribution in parallel channel heat sinks are needed.

The present study seeks to fill the research gap by tailoring the flow distribution of the cooling fluid in parallel mini-channel heat sinks subjected to non-uniform multiple-peak heat flux, so as to minimize the peak temperature on the heating surface. For this purpose, a 3D heat sink comprising 16 parallel straight mini-channels is used as a model for study. Non-uniform heat flux with multiple Gaussian peaks are set to the base heating surface of the heat sink to represent the real hot spots generated by the electronic devices. An original optimization algorithm is developed to adjust the channel inlets of the mini-channels according to the temperature distribution on the base surface. Consequently, the fluid flow distribution among the mini-channels is tailored step by step, reducing the peak temperature (global thermal resistance) of the heat sink. The effectiveness of the optimization algorithm will be illustrated and discussed through various numerical examples.

It should be noted that acting on the channel inlets (also called perforated baffle in some studies) to regulate the flow distribution among parallel channels or tubes is not new but has been proposed and proven to be effective by many researchers [20,33-35]. But most of them use homogeneous or non-homogeneous insertion baffle as a convenient way to improve the flow uniformity. Our earlier study [34] proposed an optimized baffle geometry that generates non-uniform flow distributions for absorbing heat in a high-temperature solar receiver. But the heat flux considered is single-peak Gaussian shape and the targeted flow distribution profile is predefined. The current study goes a step further by addressing the multiple peak heat flux condition. The peak temperature of the heating surface is minimized by directly adjusting the widths of the channel inlets; the resulting flow distribution profile is thus consequential and adapted.

The contributions of this paper are important because they will expand the limited literature and provide additional insights into the flow distribution issue in heat sinks subjected to the non-uniform multiple-peak heat source. The results obtained may promote the better application of this thermal management technology in various energy units and systems, including solar collectors [36], concentrating photovoltaic/thermal (CPV/T) receivers [37], the battery pack of electric vehicles, integrated reactor-heat exchangers [3840], etc.

The rest of the paper is organized as follows. The 3D numerical heat sink model and the methodology for flow distribution optimization are described in detail in Section 2. Numerical results on the thermohydrodynamic characteristics of the heat sink are presented and analyzed in Section 3. Finally, in Section 4, main findings and perspectives are summarized. 


\section{Methodology}

In this section, the heat sink model and optimization algorithm are firstly presented. Then the computational fluid dynamics (CFD) parameters for numerical testing and the performance indicators are introduced.

\subsection{Heat sink model}

Fig. 2 shows the geometry and dimensions of the heat sink model used in this study. The core part of the heat sink is a cuboid solid monoblock, with the overall dimensions of $54 \mathrm{~mm}$ in length ( $x$-direction), $54 \mathrm{~mm}$ in width ( $y$-direction) and $6 \mathrm{~mm}$ in height (z-direction). It has a U-type flow arrangement, with a single inlet and outlet tube (i.d.: $5 \mathrm{~mm}$ ) aligned with the central line, perpendicular to the heating surface (and the cooling parallel channels). The length of the global inlet/outlet tubes is $18 \mathrm{~mm}$ and the distance between their centers is $45 \mathrm{~mm}$. Between the global inlet and the outlet tubes, the fluid domain consists of three sections: the inlet distributing manifold, 16 parallel straight channels, and the outlet collecting manifold. Both the inlet and outlet fluid manifolds have a rectangular shape of $50 \mathrm{~mm}$ in length, $8 \mathrm{~mm}$ in width, and $2 \mathrm{~mm}$ in height. Mini channels with a rectangular cross-section of $1 \mathrm{~mm}$ in width and $2 \mathrm{~mm}$ in height are arranged in parallel, connecting the inlet manifold and the outlet manifold. The distance between the axes of two neighboring channels is $3 \mathrm{~mm}$ and the total length of the straight mini-channels is equal to $34 \mathrm{~mm}$. For the convenience of description, these channels are indexed by $i$ from 1 to 16 along the $x$ direction. The inlet of the mini-channels $(2 \mathrm{~mm}$ in length) is subject to enlarging or narrowing by the optimization algorithm so as to adjust the mass flow rate of the cooling fluid flowing inside.

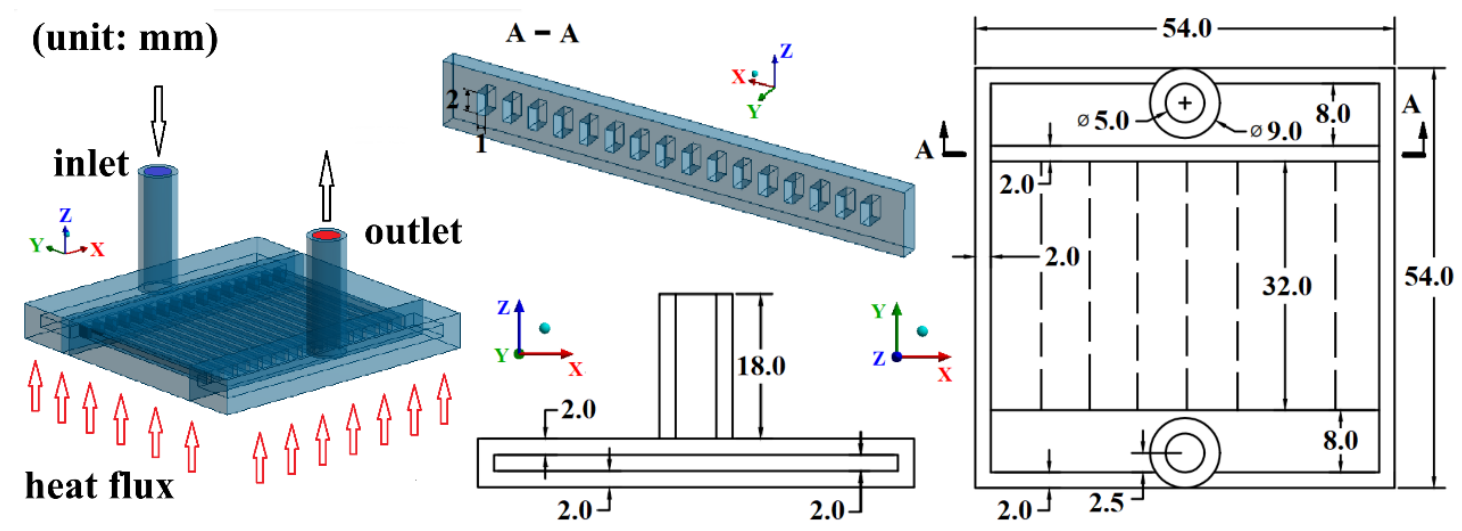

Figure 2. Schematic view and dimensions of the heat sink model (unit: $\mathrm{mm}$ )

The wall thickness of the solid envelope that encloses the fluid domain is equal to 2 $\mathrm{mm}$. The base wall of the heat sink is a flat square surface $\left(54 \times 54 \mathrm{~mm}^{2}\right)$, receiving nonuniform multiple-peak heat flux generated by the electronic device (e.g., MCM). The heat 
will be firstly transferred by conduction in the solid part, and then by convection to the cooling fluid.

\subsection{Optimization algorithm}

This sub-section presents the basic principles of the optimization algorithm for tailoring the cooling fluid flow distribution in the parallel straight-channels heat sink. The following assumptions and simplifications have been made for this study:

- Steady-state, incompressible Newtonian fluid flow;

- Negligible viscous heating effect;

- Negligible radiation heat transfer; negligible heat loss to the environment.

- No phase change of the cooling fluid.

Based on the mass and energy conservation, the following equations could be written:

$$
\begin{gathered}
m_{\text {tot }}=m_{\text {in }}=\sum_{i=1}^{16} m_{i}=m_{\text {out }} \\
Q_{\text {tot }}=\int_{A} q d A=m_{\text {tot }}\left(C p_{\text {out }} T_{\text {out }}-C p_{\text {in }} T_{\text {in }}\right)
\end{gathered}
$$

Where $m_{\text {tot }}, m_{i n}, m_{i}$ and $m_{\text {out }}$ are the total, inlet, $i$ th mini-channel and outlet mass flow rate of the cooling fluid, respectively. $Q_{t o t}$ is the total heating power; $q$ is the heat flux at the heating surface of the heat sink; $C p_{\text {out }}$ and $C p_{\text {in }}$ are the specific heat of the outlet and inlet fluid and $T_{\text {out }}$ and $T_{\text {in }}$ are the inlet and outlet fluid temperature, respectively. Different from many earlier relevant studies, the heat flux $q$ treated here is no longer uniform but shows a multiple-peak form (as shown in Fig. 4 for example).

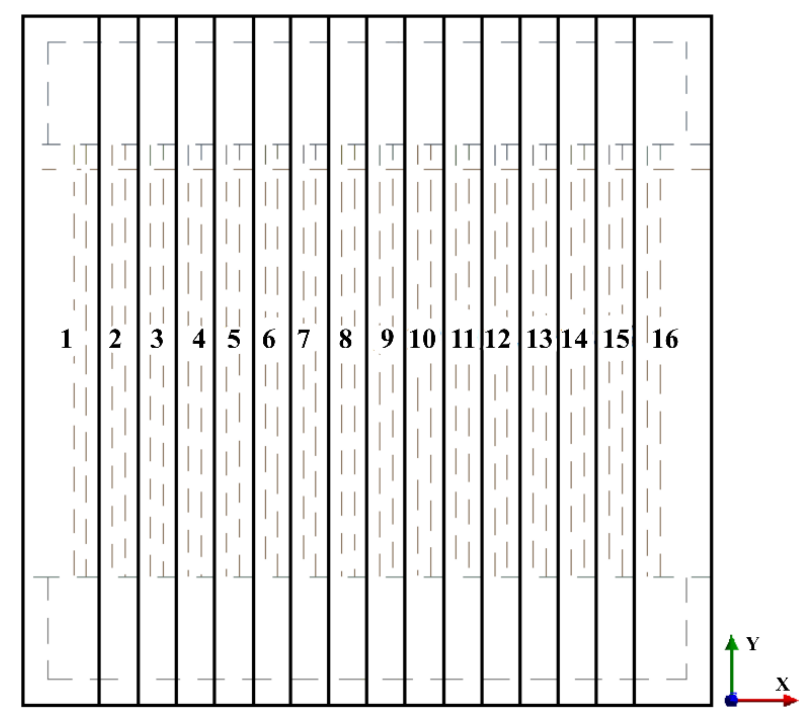

Figure 3. Base wall (heating surface) divided into 16 hypothetical planes 
The optimization algorithm is developed to determine the optimal inlet sizes of the parallel mini-channels so as to minimize the maximum temperature of the heating surface (and also the thermal resistance, cf. Eq. (24)) via tailoring the flow distribution of the cooling fluid. The method developed is deterministic, i.e. the width distribution of the channel inlets was optimized (adjusted) in a way of evolution, but not randomly generated. For this purpose, the heating surface of the heat sink was hypothetically divided into 16 monitoring planes corresponding to every mini channel, as schematically shown in Fig. 3.

$T_{i}^{\max }$ is defined as the maximum temperature of the $i$ th plane, the indexing being marked in Fig. 3. The objective of optimization may be written as:

$$
T_{i}^{\max }=\bar{T}^{\max }(i=1,2, \ldots, 16)
$$

Where $\bar{T}^{\max }$ is the mean temperature of all $16 T_{i}^{\max } \quad(i=1,2, \ldots, 16)$.

Practically, the standard deviation of the maximum temperatures of the 16 monitoring planes $\left(M F_{T} \max \right)$ is monitored, written as:

$$
M F_{T_{\max }}=\sqrt{\frac{1}{15} \sum_{i=1}^{16}\left(\frac{T_{i}^{\max }-\bar{T}^{\max }}{\bar{T}^{\max }}\right)^{2}}
$$

Given the constant total mass flow rate $\left(m_{t o t}\right)$ of the cooling fluid, the mass flow rate in each mini-channel is intended to be managed by adjusting the corresponding channel inlet width according to the temperature difference between $T_{i}^{\max }$ and $\bar{T}_{i}^{\max }$. In more detail, if $T_{i}^{\max }$ is higher than $\bar{T}_{i}^{\max }$, the higher mass flow rate is required for enhancing the cooling, thus the corresponding channel inlet width of the $i$ th mini-channel should be enlarged. And vice-versa, if $T_{i}^{\max }$ is lower than $\bar{T}_{i}^{\max }$, the mass flow rate could be reduced by narrowing the channel inlet. This variation rule is written in Eq. (5).

$$
w_{k+1, i}=w_{k, i}+\gamma\left(T_{k, i}^{\max }-\bar{T}_{k}^{\max }\right)
$$

Where $w_{k, i}$ is the width of $i$ th channel inlet for the step $k$ iteration. $\gamma$ is the adjusting factor deciding the variation amplitude of each iteration. The value of $\gamma$ for each iteration was selected considering the geometric constraints in that all the channel inlets should not be smaller than zero $\left(w_{i} \geq 0, i=1,2, \ldots, 16\right)$ and two adjacent channel inlets should not overlap $\left(w_{i}+w_{i+1} \leq 3, i=1,2, \ldots, 15\right)$ :

$$
\gamma \leq \frac{3-w_{k, i}}{T_{k, i}^{\max }-\bar{T}_{k}^{\max }}
$$




$$
\gamma \leq \frac{w_{k, i}}{\bar{T}_{k}^{\max }-T_{k, i}^{\max }}
$$

With the variation rule shown in Eq. (5), the passage ratio of the channel inlets (defined as the ratio between the total width of the channel inlets and the width of the distributing manifold) remains constant (29.6\%) during iteration, as indicated by Eq. (8).

$$
\sum_{i=1}^{16}\left(w_{k+1, i}-w_{k, i}\right)=\gamma \sum_{i=1}^{16}\left(T_{k, i}^{\max }-\bar{T}_{k}^{\max }\right)=\gamma\left(\sum_{i=1}^{16} T_{k, i}^{\max }-16 \times \bar{T}_{k}^{\max }\right)=\gamma\left(\sum_{i=1}^{16} T_{k, i}^{\max }-16 \times \frac{\sum_{i=1}^{16} T_{k, i}^{\max }}{16}\right)=0
$$

The optimization is started with the equal width of all the channel inlets, representing a conventional heat sink configuration with parallel straight channels. The optimization is considered to be completed when $M F_{T_{k}^{\max }}$ (Eq. 4) is smaller than 0.003 .

The main steps of the optimization procedure are explained as below:

(1) Input the initial geometrical parameters of the heat sink and the channel inlet width distribution (equal channel inlets at step 0 );

(2) Generate the geometry and mesh of the heat sink;

(3) Calculate the temperature and fluid flow characteristics by CFD simulation under designed working conditions and simulation setup; compute the $T_{k, i}^{\max }$ and $M F_{T_{k}^{\max }}$ of the heat sink in step $k$;

(4) If $M F_{T_{k}^{\max }}<0.003$, then export the optimal geometry of the channel inlets and end the procedure; if $M F_{T_{k}^{\max }}>0.003$, update the new geometry according to Eq. (5) and go back to step (2) for iteration.

\subsection{CFD simulation parameters}

The flow and temperature fields of the heat sink at each iteration step are calculated using CFD simulation. Governing equations under steady-state are shown as follows:

Continuity equation:

$$
\nabla \cdot(\rho \vec{v})=0
$$

Momentum conservation equation:

$$
\nabla \cdot(\rho \vec{v} \vec{v})=-\nabla p+\nabla \cdot(\overline{\bar{\tau}})+\rho \vec{g}+\vec{F}
$$


Where $p$ is the static pressure; $\overline{\bar{\tau}}$ is the stress tensor; $\rho \vec{g}$ and $\vec{F}$ are the gravitational body force and external body force.

Energy equation:

$$
\nabla \cdot(\vec{v}(\rho E+p))=\nabla \cdot\left(\lambda_{e f f} \nabla T-\sum_{j} h_{j} \vec{j}_{j}+\left(\overline{\bar{\tau}}_{e f f} \cdot \vec{v}\right)\right)+S_{h f}
$$

Where $S_{h f}$ is the volumetric heat source in the fluid; $\lambda_{e f f}$ is the effective conductivity; $h$ is the sensible enthalpy; $\overline{\bar{\tau}}_{\text {eff }}$ is the effective shear stress. To predict turbulent flow pattern, additional turbulence model should be employed.

For solid zone, the energy transport equation is:

$$
\nabla \cdot\left(\lambda_{s} \nabla T\right)+S_{h s}=0
$$

Where $S_{h s}$ is the heat source within the solid.

\begin{tabular}{|c|c|c|c|}
\hline \multicolumn{2}{|l|}{ Property } & \multirow{2}{*}{\multicolumn{2}{|c|}{$\begin{array}{l}\text { Fitting correlation (temperature range: } 293 \mathrm{~K}-360 \mathrm{~K} \text { ) } \\
\qquad \rho=-2.604 \times 10^{-8} T^{4}+4.719 \times 10^{-5} T^{3}-3.279 \times 10^{-2} T^{2}+9.469 T+43.486\end{array}$}} \\
\hline \multirow[t]{5}{*}{ Water } & Density & & \\
\hline & $\left(\mathrm{kg} \cdot \mathrm{m}^{-3}\right)$ & 1 & ) \\
\hline & $\begin{array}{l}\text { Dynamic } \\
\text { viscosity } \\
\left(\mathrm{kg} \cdot \mathrm{m}^{-1} \cdot \mathrm{s}^{-1}\right) \\
\end{array}$ & $\mu=2.414 \times 10^{-5} \times 10^{\frac{247.8}{T-140}}$ & (14) \\
\hline & $\begin{array}{l}\text { Thermal } \\
\text { conductivity } \\
\left(\mathrm{W} \cdot \mathrm{m}^{-1} \cdot \mathrm{K}^{-1}\right)\end{array}$ & $\lambda_{f}=-8.356 \times 10^{-6} T^{2}+6.530 \times 10^{-3} T-0.598$ & (15) \\
\hline & $\begin{array}{l}\text { Specific heat } \\
\left(\mathrm{J} \cdot \mathrm{kg}^{-1} \cdot \mathrm{K}^{-1}\right)\end{array}$ & $C p_{f}=4182$ & (16) \\
\hline \multirow[t]{3}{*}{ Aluminum } & $\begin{array}{l}\text { Specific heat } \\
\left(\mathrm{J} \cdot \mathrm{kg}^{-1} \cdot \mathrm{K}^{-1}\right)\end{array}$ & $C p_{s}=3.973 \times 10^{-6} T^{3}-5.667 \times 10^{-3} T^{2}+3.069 T+380.170$ & $(17)$ \\
\hline & $\begin{array}{l}\text { Thermal } \\
\text { conductivity } \\
\left(\mathrm{W} \cdot \mathbf{m}^{-1} \cdot \mathbf{K}^{-1}\right)\end{array}$ & $\lambda_{s}=202.4$ & (18) \\
\hline & $\begin{array}{l}\text { Density } \\
\left(\mathrm{kg} \cdot \mathrm{m}^{-3}\right)\end{array}$ & $\rho=2719$ & (19) \\
\hline
\end{tabular}

Table 1. Thermal-physical properties of solid and fluid used for simulation [41-43]

In this study, geometries and meshes were generated using different modules of ANSYS Workbench 18.2. Hexahedral elements and the multi-zone method were applied for meshing fluid and solid domains. Inflation, sizing meshing methods were adopted at the 
solid-fluid interface and the corners of the fluid domain to capture the boundary layer region of the fluid flow.

Water was used as the cooling fluid and aluminum was chosen as the solid material of the heat sink body. Their temperature-dependent or constant thermophysical properties are expressed by the equations listed in Table 1.

For the fluid zone, velocity inlet normal to the inlet boundary surface was set, with a temperature at $293 \mathrm{~K}$. The inlet velocity was set to be constant and equal to $0.5 \mathrm{~m} \cdot \mathrm{s}^{-1}$, $0.55 \mathrm{~m} \cdot \mathrm{s}^{-1}, 0.6 \mathrm{~m} \cdot \mathrm{s}^{-1}, 0.65 \mathrm{~m} \cdot \mathrm{s}^{-1}$ and $0.7 \mathrm{~m} \cdot \mathrm{s}^{-1}$ (with inlet Re number (Eq. 26): 2488, 2737, 2986, 3234 and 3483, respectively, the corresponding mean channel Re number (Eq. 27): $406,447,487,528$ and 569, respectively) in different cases. Pressure outlet boundary was set for the outlet surface with the gauge pressure value being zero. All the walls for channels were defined as non-slip conditions. For the solid zone, all walls were considered as adiabatic except the heating surface (base wall). For the latter, two-peak and five-peak heat flux were defined and tested, respectively, as shown in Fig. 4. Their 2D surface heat flux Gaussian repartitions are given by Eq. 20 .

$$
q(x, y)=\sum_{i=1}^{N} q_{i}(x, y)=\sum_{i=1}^{N} B_{i} e^{-\frac{\left(x-x_{i}\right)^{2}+\left(y-y_{i}\right)^{2}}{2 \sigma_{i}^{2}}}
$$

where $N$ represents the number of heat peaks ( 2 or 5 ), a peak located at $x=x_{i}, y=y_{i}$ presents a maximum local heat flux; $B_{i}, \sigma_{i}$ represents the spatial spread of the peak. The total heat $Q_{i}$ generated by a peak (if the plate had infinite extent) can be computed by:

$$
Q_{i}=\iint_{\mathbb{R}^{2}} q_{i}(x, y) d x d y=2 \pi B_{i} \sigma_{i}^{2}
$$

The different values of $x_{i}, y_{i}, B_{i}, \sigma_{i}$ and $Q_{i}$ are summarized in Table 2.

\begin{tabular}{|c|c|c|c|c|c|}
\hline \multicolumn{6}{|c|}{ Two peak heat flux case: $N=2$} \\
\hline$i$ & $x_{i}(\mathrm{~mm})$ & $y_{i}(\mathrm{~mm})$ & $B_{i}\left(\mathrm{~W} \cdot \mathrm{cm}^{-2}\right)$ & $\sigma_{i}(\mathrm{~mm})$ & $Q_{i}(\mathrm{~W})$ \\
\hline 1 & -13.5 & 16 & 130 & 10 & 817 \\
\hline 2 & 13.5 & 24 & 70 & 10 & 440 \\
\hline \multicolumn{6}{|c|}{ Five peak heat flux case: $N=5$} \\
\hline 1 & -16 & 28 & 120 & 7.2 & 391 \\
\hline 2 & 16 & 28 & 70 & 5 & 110 \\
\hline 3 & 0 & 19 & 90 & 5.7 & 184 \\
\hline 4 & -16 & 10 & 70 & 5 & 110 \\
\hline 5 & 16 & 10 & 120 & 7.2 & 391 \\
\hline
\end{tabular}

Table 2. The values of constants used for two-peak and five-peak heat flux cases 

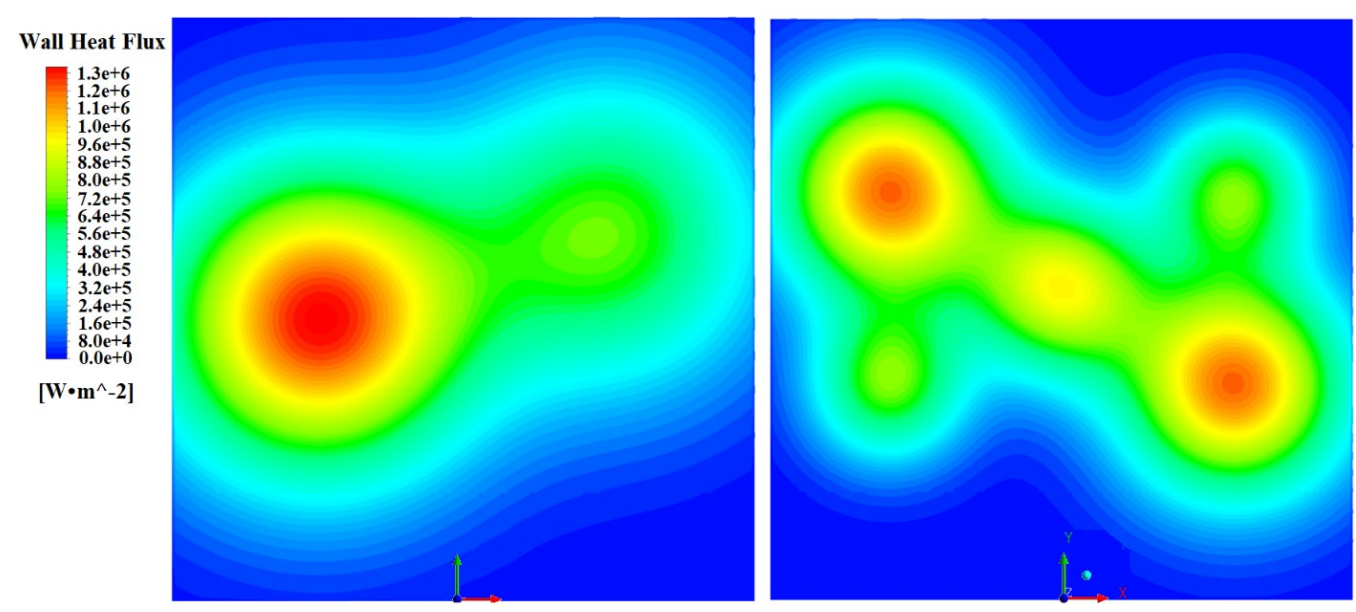

Figure 4. Two-peak and five-peak heat flux at the base wall

The total power of the heat source is constant $(Q=1130 \mathrm{~W})$ and the average heat flux (power density) for the base wall $\left(q_{\text {avg }}=38.75 \mathrm{~W} \cdot \mathrm{cm}^{-2}\right)$ are identical for both heat flux settings, as indicated in Eqs. (22) and (23). The difference between $Q$ and $\sum_{i} Q_{i}$ is due to the truncation effect of the Gaussian on the limited extent plate. The maximum peak values for the two cases are slightly different, i.e. $130 \mathrm{~W} \cdot \mathrm{cm}^{-2}$ at $\left(x_{1}, y_{1}\right)$ for two-peak heat flux and $120 \mathrm{~W} \cdot \mathrm{cm}^{-2}$ at $\left(x_{1}, y_{1}\right)$ and $\left(x_{5}, y_{5}\right)$ for five-peak heat flux, respectively.

$$
\begin{gathered}
Q=\iint_{A} q(x, y) d A=1130(\mathrm{~W}) \\
q_{\text {avg }}=\frac{Q}{A}=\frac{1}{A} \iint_{A} q(x, y) d A=38.75\left(\mathrm{~W} \cdot \mathrm{cm}^{-2}\right)
\end{gathered}
$$

Different from other non-uniform heat sources e.g., several squares with uniform heat flux in each specific area, the Gaussian-shaped heat flux has been chosen in this study considering the gradient of real heat flux generated by the electronic components. Note that it can be replaced by other heat flux profiles without much influencing the effectiveness of the algorithm. The two-peak case represents the asymmetry heat flux profile, while the fivepeak case considers the centrosymmetric heat flux condition.

In this study, 3D fluid flow simulations were performed under steady-state with heat transfer, using a commercial code FLUENT (version 18.2). The gravity effect was also considered. $k-\varepsilon$ RNG model was used to simulate the turbulent flow, providing better accuracy for rapidly strained flows and swirling flows at relatively low Reynolds number condition. For the pressure-velocity coupling, the SIMPLE method was used. For discretization, the second-order spatial discretization scheme was chosen for pressure and second-order upwind differentiation for momentum, turbulent kinetic energy, and turbulent dissipation rate. The solution was considered to be converged when (i) the maximum temperature of the heating surface and the pressure drop were constant from one iteration to the next (less than $0.5 \%$ variation), and (ii) the normalized residuals were lower than $10^{-8}$ for the energy equation and $10^{-5}$ for other governing equations. 
For each iteration step of the optimization algorithm, MATLAB R2016b was used for data post-processing of the computed flow and temperature profiles from FLUENT, to calculate the size variation of each channel inlet according to Eq. (5) and to pass the renewed geometric coordinates to Ansys Workbench for a new CFD simulation.

A grid independence study was conducted with the increasing number of total elements from 0.28 million to 2.27 million. Table 3 shows the values of pressure drop and maximum solid temperature obtained with different grids under an inlet mass flow rate of $0.011731 \mathrm{~kg} \cdot \mathrm{s}^{-1}\left(V_{i n}=0.6 \mathrm{~m} \cdot \mathrm{s}^{-1}\right)$. A pressure drop variation within $1 \%$ and a maximum solid temperature within $0.7 \mathrm{~K}$ could be achieved with the grid elements higher than 1.14 million. Comparisons were also made on the fluid velocity profiles at the centerline of the outlet surface ( $x$-direction). Again, there is no obvious difference for grids with elements number higher than 1.14 million. As a result, this grid with 1.14 million elements $(0.5$ million elements for fluid zone and 0.64 elements for solid zone) has been chosen for the present study considering a tradeoff between the computation cost and accuracy. The calculation was carried out in a workstation with Intel (R) processor Xeon (R) CPU E5-2620 and 32 GB memory. Two hours were needed for each optimization step.

Table 3. Comparison of the pressure drop, the maximum temperature, and the velocity profile for different

\begin{tabular}{|c|c|c|c|c|c|c|}
\hline \multicolumn{7}{|c|}{ tested grids } \\
\hline Grid (million elements) & 0.28 & 0.52 & 0.75 & 1.14 & 1.76 & 2.27 \\
\hline Pressure drop $(\mathrm{Pa})$ & 1231.3 & 1216.6 & 1206.4 & 1196.7 & 1191.4 & 1185.4 \\
\hline $\begin{array}{l}\text { Maximum temperature at the } \\
\text { heating surface }(K)\end{array}$ & 384.8 & 383.9 & 384.2 & 383.8 & 384.0 & 384.4 \\
\hline $\begin{array}{l}\text { Velocity profile at the centerline of } \\
\text { the outlet surface }\end{array}$ & & $\begin{array}{c}0.3 \\
0.2 \\
0.1 \\
0.0\end{array}$ & & on of $\mathrm{x}(\mathrm{mm})$ & $2^{2}$ & \\
\hline
\end{tabular}

\subsection{Performance indicators}

The performance of the heat sink was evaluated by the maximum temperature of the base wall, the global thermal resistance, and the pressure drop. The global thermal resistance $\left(R_{t h}\right)$ of the heat sink is calculated by Eq. (24): 


$$
R_{t h}=\frac{T_{\text {base }}^{\max }-T_{\text {in }}}{Q}\left(\mathbf{K} \cdot \mathbf{W}^{-1}\right)
$$

Where $T_{\text {base }}^{\max }$ is the maximum temperature at the heating surface (base wall) of the heat sink, $T_{i n}$ is the inlet fluid temperature (293 K), $Q$ is the total heating power $(1130 \mathrm{~W})$.

The pressure drop in different sections of the fluid domain is also monitored:

$$
\Delta P_{t o t}=\Delta P_{d i s}+\Delta P_{c h}+\Delta P_{c o l} \quad(\mathbf{P a})
$$

Where $\Delta P_{d i s}, \Delta P_{c h}$ and $\Delta P_{c o l}$ stands for the pressure drop in the distributor section, the parallel channels section (including the channel inlets with variable widths), and the collector section, respectively.

The inlet Reynolds number and the mean Reynolds number in the mini-channels are calculated by Eqs. (26) and (27), respectively.

$$
\begin{aligned}
& \mathrm{Re}_{i n}=\frac{\rho_{f} V_{i n} D_{i n}}{\mu_{f}}=\frac{4 m_{i n}}{\pi \mu_{f} D_{i n}} \\
& \overline{\operatorname{R}}=\frac{\rho_{f} \bar{V}_{c h} D_{c h}}{\mu_{f}}=\frac{m_{i n}}{4 \pi \mu_{f} D_{c h}}
\end{aligned}
$$

Where $V_{i n}$ and $V_{c h}\left(\mathrm{~m} \cdot \mathrm{s}^{-1}\right)$ are the inlet and mean channel velocity, respectively. $D_{i n}$ and $D_{c h}$ $(\mathrm{m})$ are the hydraulic diameters of the global inlet port and the mini channel, respectively.

Nondimensional parameters $m^{*}$ and $w^{*}$ are defined as follows.

$$
\begin{aligned}
& m^{*}=\frac{m_{i}}{\bar{m}} \\
& w^{*}=\frac{w_{i}}{\bar{w}}
\end{aligned}
$$

Where $\bar{m}$ and $\bar{w}$ are the mean channel mass flow rate and the mean width of channel inlets, respectively.

\section{Results and discussions}

In this section, the flow distribution and thermal characteristics of the straight mini-channel heat sink with optimized channel inlets are shown and compared with the conventional heat sink with equal channel inlets. In addition, a parametric study and a 
robustness test on the relationship between the tailored flow distribution, the overall thermal resistance, and the total pressure drop are reported.

Fig. 5 shows that the value of $M F_{T^{\max }}$ (Eq. 4) evolves along with the increasing step number. It took the two-peak heat flux case 14 iteration steps to achieve the convergence $\left(M F_{T} \max <0.003\right)$, and for the case of five-peak heat flux, 10 iteration steps were needed.

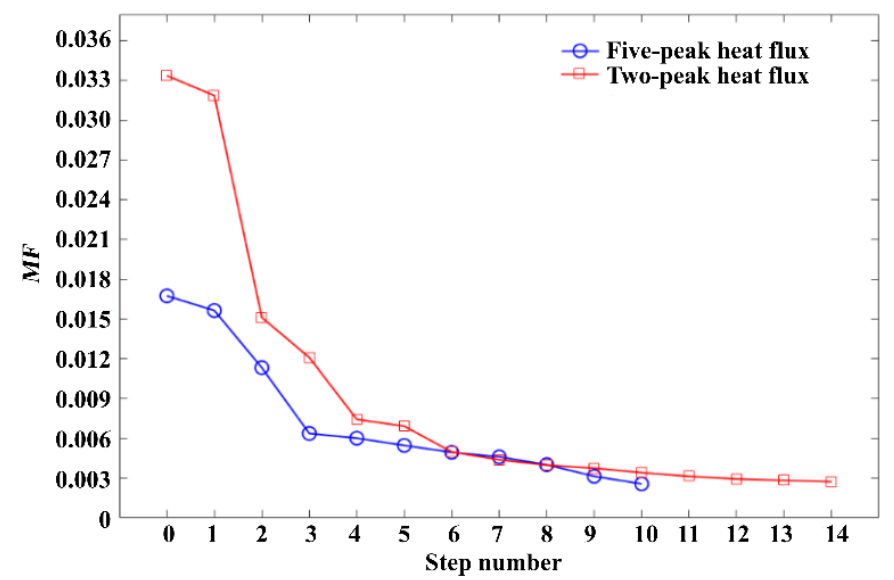

Figure 5. Evolution of $M F$ value along with the optimization step for two and five-peak heat flux cases

\subsection{Flow distribution characteristics}

Figs. 6(a) and (b) present the widths of channel inlets and the flow distribution characteristics of cooling fluid among mini-channels as a function of optimization step for two-peak heat flux case. From Fig. 6(a), it can be seen that the largest channel inlet is located at the position where peak temperature appears for all steps (except for step 0). As the iteration step proceeds, the widths of the channel inlet for channel number 1-6 gradually enlarge, much broader than those for channel number 7-16 due to the location of the larger hot spot with higher temperatures. With the constraint of constant passage ratio, the inlet widths of channels 8-16 have all been narrowed, despite a (smaller) heat flux peak located in this region.

This variation of the channel inlet widths results in the evolution of the fluid flow distribution characteristics, as shown in Fig. 6(b). For the starting step 0 (equal channel inlet widths), the shape of the mass flow distribution curve is almost symmetric with respect to the centerline. Middle channels (No. 8 and 9) receive the highest mass flow rate, and it gradually decreases for the channels located closer to the edges (No. 1 and 16). This is because of the middle location of inlet/outlet tubes (U-type flow arrangement). The unmatched flow rate distribution to the heat flux peaks causes inevitably the temperature hot spots (as shown in Fig. 8). Generally speaking, the evolution of the flow distribution curve shows a similar tendency as the evolution of the inlet widths curve, indicating an 
effective control of the channel mass flow rate by adjusting the inlet widths. Under the constraint of constant total mass flow rate, a large proportion of the cooling fluid has been guided to channels 1-8, where the larger heat flux peak is located.

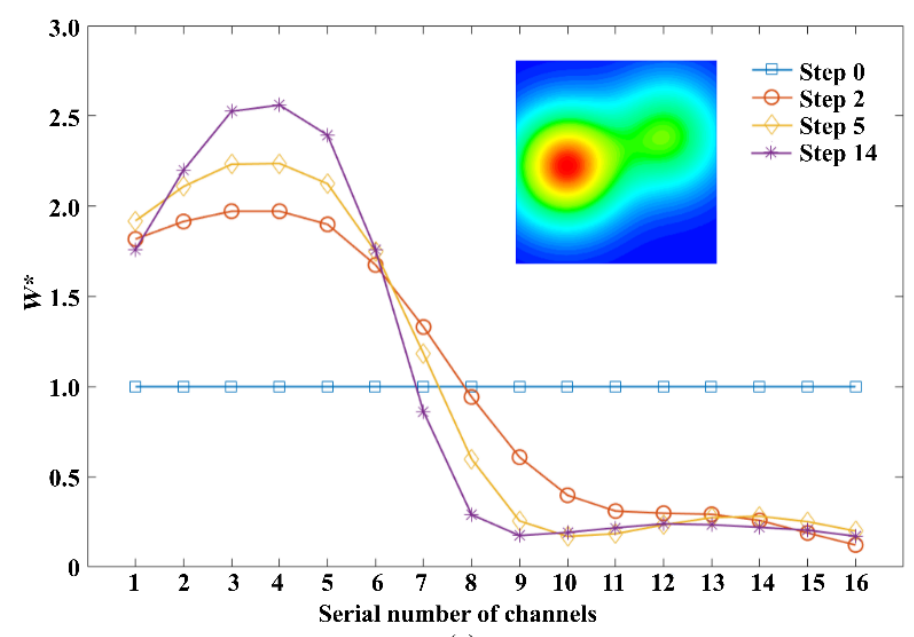

(a)

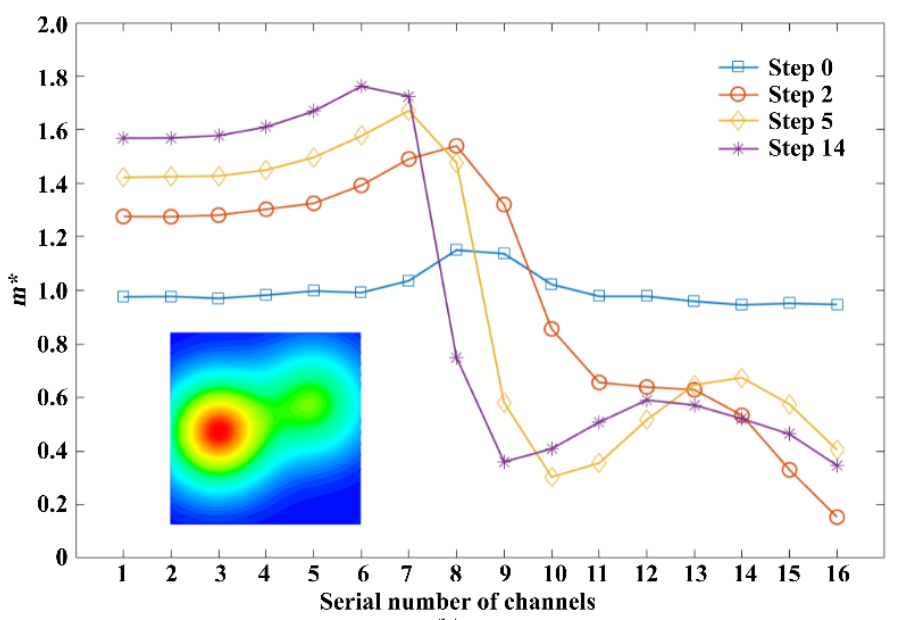

(b)

Figure 6. Channel inlet width evolution (a) and flow distribution (b) among mini-channels for step 0, step 2, step 5 and step 14 of the two-peak heat flux case

Figs. 7(a) and (b), analogous to Fig. 6, are for the five-peak heat flux case. The channel inlet widths curve firstly tends to form the bathtub shape in step 2, and then gradually generates the three peaks shape at the middle and two edge sides in step 10 . This is in line with the fact that the channel inlet widths in channels are modified in each step according to the temperature hot spots on the heating surface. Even if the heat flux is centrosymmetric, one of the two highest heat flux peaks close to the distributing manifold has the lower temperature hot spot than the other near to the collecting manifold. Before the coolant passes through the highest heat flux point close to the global outlet tube, it has already absorbed some quantity of heat in the straight channels. As a result, the inlet widths of the channels corresponding to the highest heat flux peak close to the outlet become the largest at the final step, as clearly shown in Fig. 7(a). 


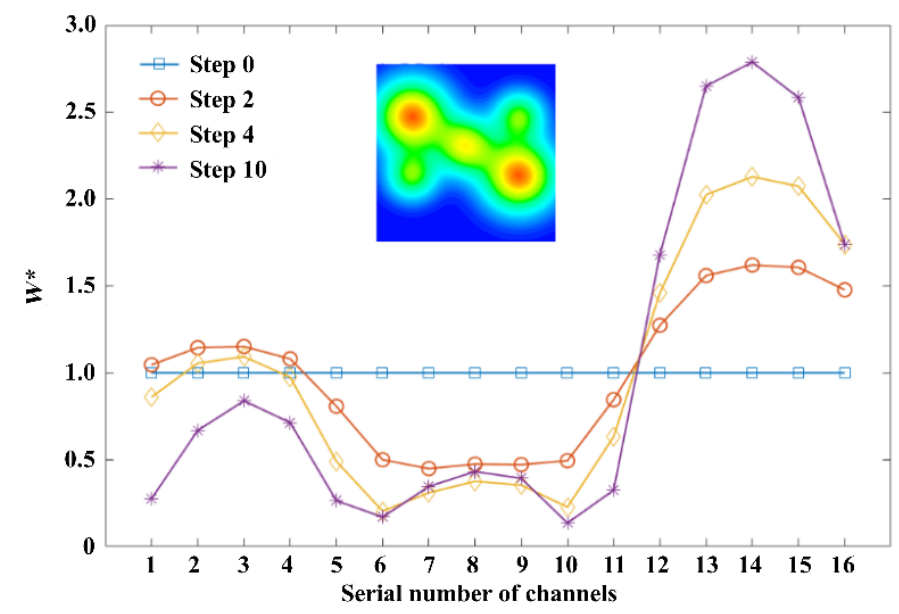

(a)

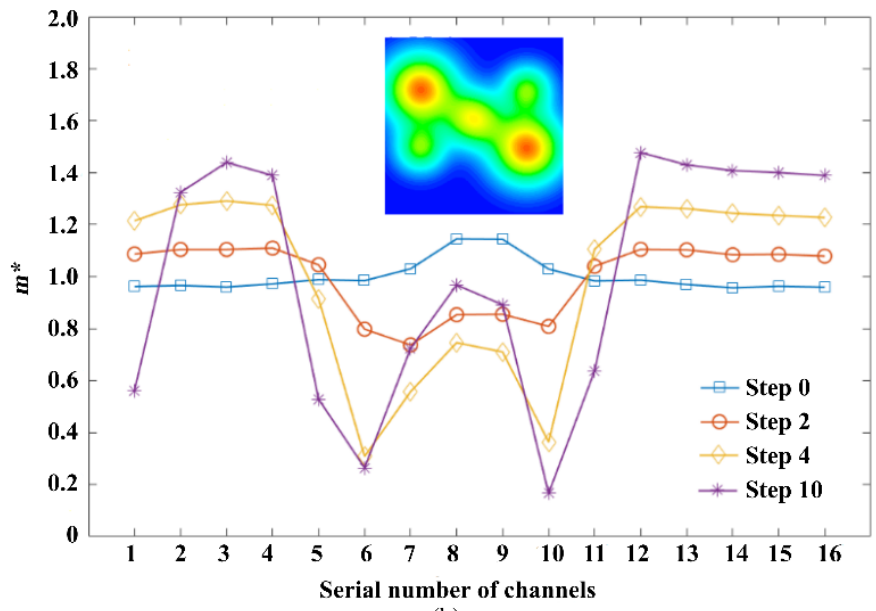

(b)

Figure 7. Channel inlet width evolution (a) and flow distribution (b) among mini-channels for step 0 , step 2 , step 4 and step 10 of the five-peak heat flux case

Regarding the flow distribution shown in Fig. 7(b), the mass of cooling fluid is guided towards the edges, and more mass flow rate should be delivered to the location situated the highest heat flux (channels No. 13-15). The sum of mass flow rates allocated to channels No. 12-16 is higher than that allocated to channels No. 1-5 at step 10, mainly due to the cooling capacity difference of coolant as discussed above.

\subsection{Temperature fields}

Fig. 8 shows the evolution of temperature cartography on the heating surface along with the optimization steps for the two-peak heat flux case. For step 0 , the maximum temperature occurs in monitoring planes 3 and 4 where the larger heat flux peak is located. By running the optimization algorithm, the higher amount of heat in this area is absorbed and efficiently evacuated owing to the broadened channel inlets and the increased mass flow rate of cooling fluid. Step by step, the hot spots largely disappear and the maximum temperatures of the 16 monitoring planes are (almost) equalized. 

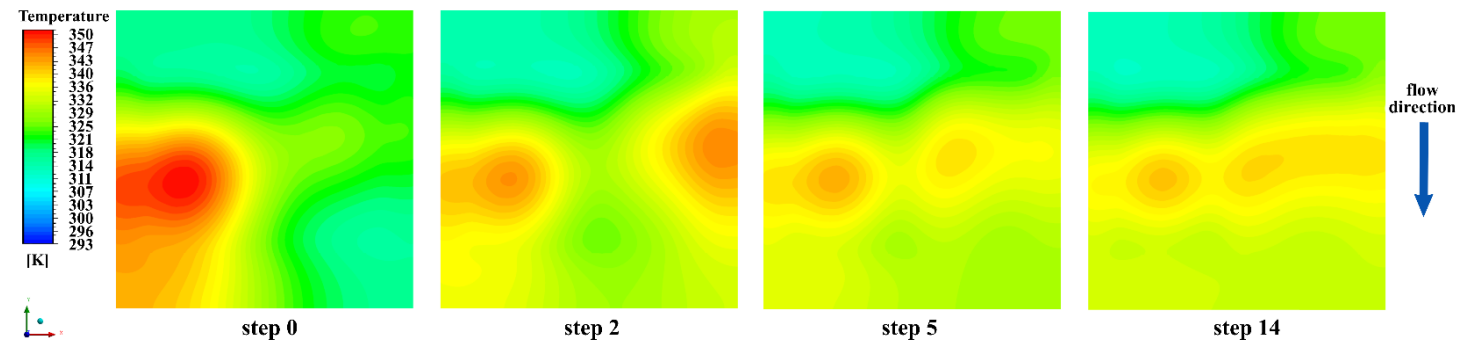

Figure 8. Temperature cartography on the base wall of the heat sink at optimization step 0 , step 2 , step 5 and step 14 for the two-peak heat flux case $\left(q_{\text {avg }}=38.75 \mathrm{~W} \cdot \mathrm{cm}^{-2} ; V_{\text {in }}=0.6 \mathrm{~m} \cdot \mathrm{s}^{-1}\right)$

Similarly, Fig. 9 depicts the temperature cartography evolution for the five-peak heat flux case. For equal channel inlet condition, the diagonal arrangement of five heat flux peaks does not results in 5 diagonal temperature hot spots because the heat generated near the distributing manifold could be more efficiently absorbed by the cooling fluid at the lower temperature. In contrast, the temperature hot spot close to the collecting manifold is rather obvious, the maximum temperature being $347.44 \mathrm{~K}$. With the optimization algorithm proceeds, the hot spot occurring in monitoring planes $12-16$ begins to decrease and diagonally extends to the middle and left parts of the base wall. At the final step 10, the maximum temperatures of the 16 monitoring planes are (almost) equalized and the peak temperature of the base wall can be reduced to $341.5 \mathrm{~K}$.
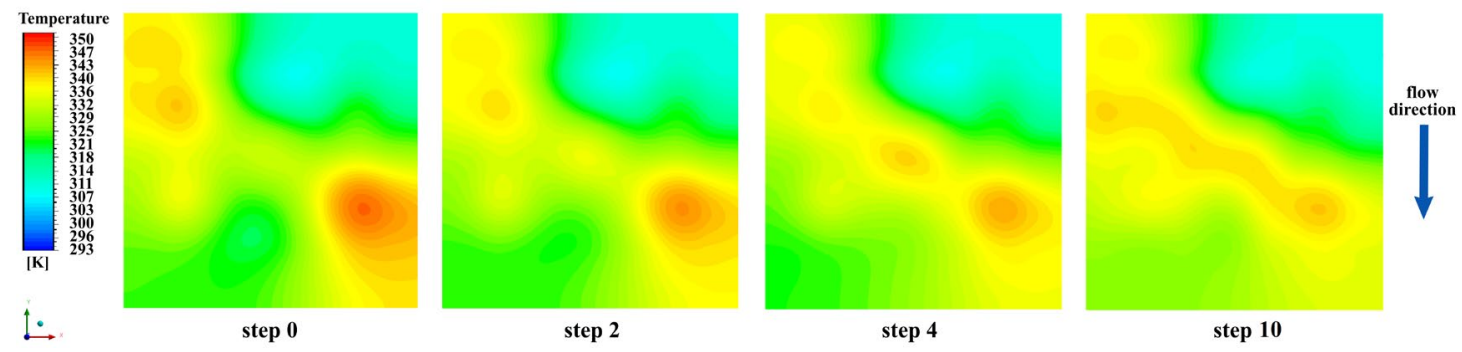

Figure 9. Temperature cartography on the base wall of the heat sink at optimization step 0, step 2, step 4 and step 10 for the five-peak heat flux case $\left(q_{a v g}=38.75 \mathrm{~W} \cdot \mathrm{cm}^{-2} ; V_{i n}=0.6 \mathrm{~m} \cdot \mathrm{s}^{-1}\right)$

$T_{i}^{\max }$ values of the monitoring planes are shown in Fig. 10. For the two-peak heat flux case, the largest difference between the maximum temperatures of the monitoring planes is about $27 \mathrm{~K}$ at step 0 (equal channel inlet widths). This temperature difference becomes smaller as the optimization iteration proceeds and finally reaches $3.4 \mathrm{~K}$ at step 14 . It may be observed that the evolution of the $T_{i}^{\max }$ curve shown in Fig. 10(a) follows the reverse trend of the channel inlet widths curve shown in Fig. 6(a). The initially equal channel inlet widths are adjusted by our algorithm step by step to flatten the $T_{i}^{\max }$ curve, indicating the effectiveness of the variation rule as proposed in Eq. (5). Similarly, Fig. 10(b) shows the evolution of the $T_{i}^{\max }$ values of the monitoring planes for the five-peak heat flux case. The difference between the maximum temperatures is reduced from about $15 \mathrm{~K}$ at step 0 to smaller than $3 \mathrm{~K}$ at step 10 . Compared to the two-peak heat flux case with the same area-weighted average power density, the five-peak case with more heat flux peaks shows a 
relatively more uniform temperature distribution. As a result, it costs fewer iteration steps to reach the optimization criterion.

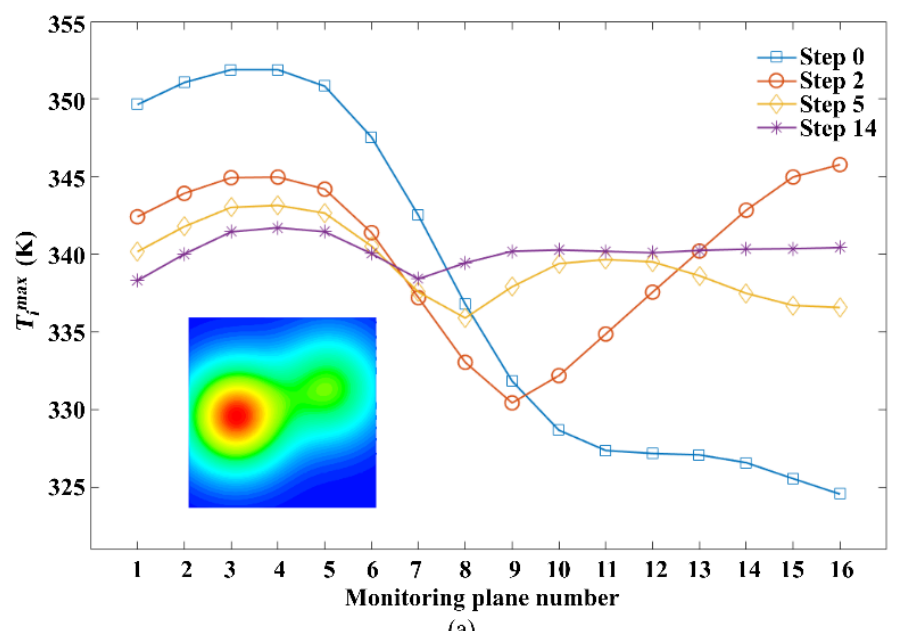

(a)

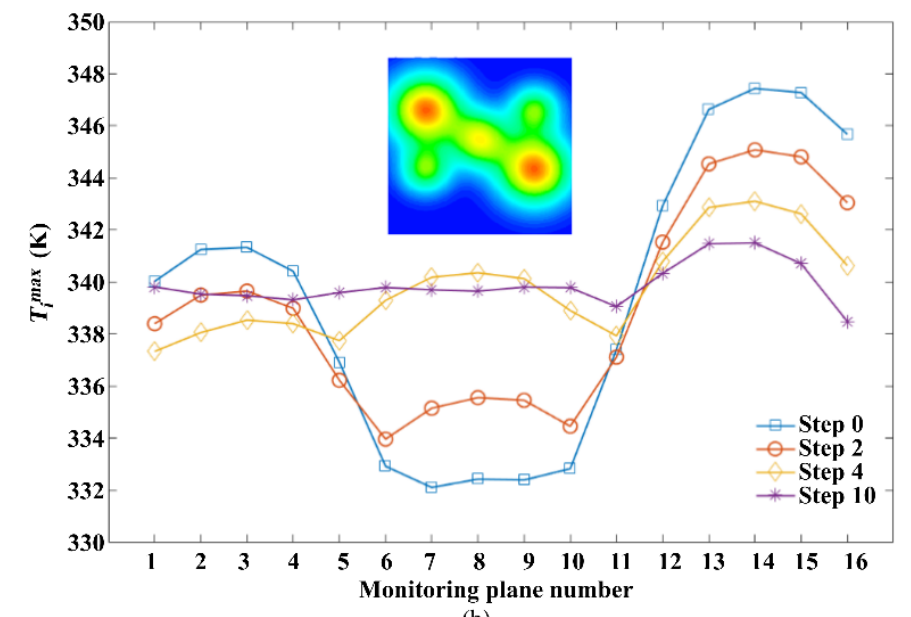

(b)

Figure 10. $T_{i}^{\max }$ in each monitoring plane as a function of optimization step for (a) two-peak heat flux case and (b) five-peak heat flux case

The maximum temperature at the base wall as a function of the optimization step is plotted in Fig. 11 for both the two-peak and five-peak cases. The reduction of maximum temperature is significant, reaching $10 \mathrm{~K}$ and $7 \mathrm{~K}$ for two-peak and five-peak cases, respectively. Recall that every $10 \mathrm{~K}$ reduction of maximum junction temperature could double the service time of the electronic devices by a factor of 2 [3]. It may be observed that the maximum temperature of the base wall decreases sharply for the first four optimization steps, mainly because of the large difference between the $T_{i}^{\max }$ and the average value $\bar{T}^{\max }$. The slope of the maximum temperature curve becomes smaller for the rest steps (about 2-3 K reduction) and finally stabilizes at the value of $341.7 \mathrm{~K}$ (two-peak case) and $341.5 \mathrm{~K}$ (five-peak case), respectively. 


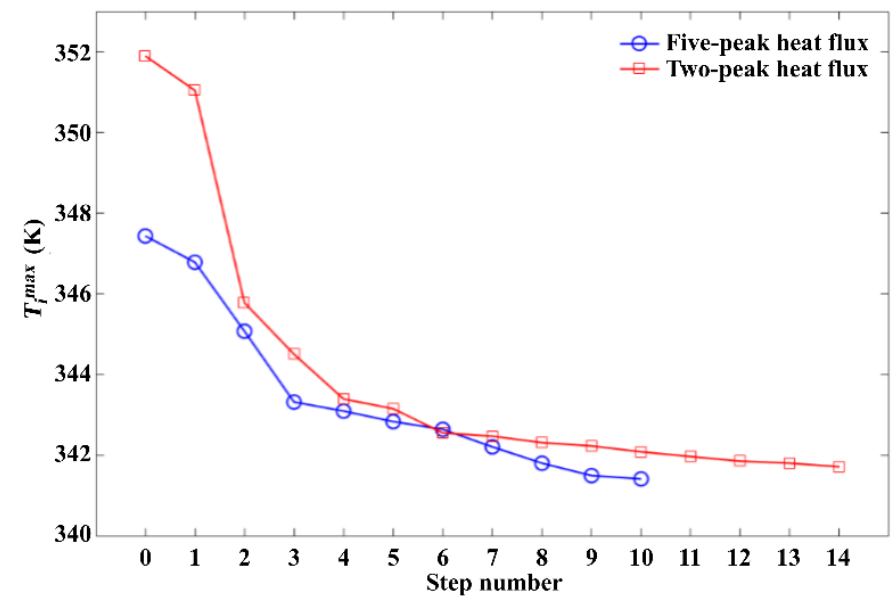

Figure 11. Maximum temperature evolution for two and five peaks heat flux cases

\subsection{Pressure drop characteristics}

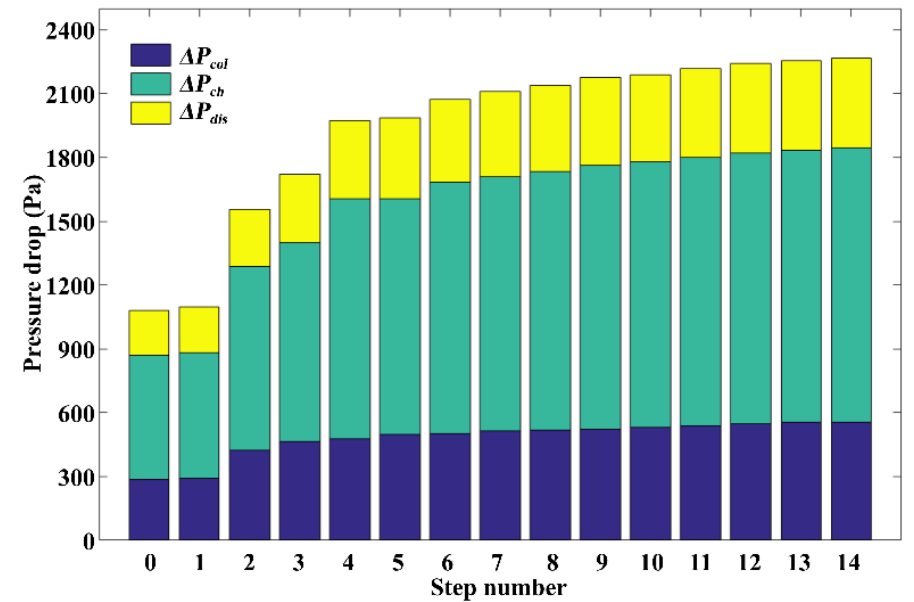

(a)

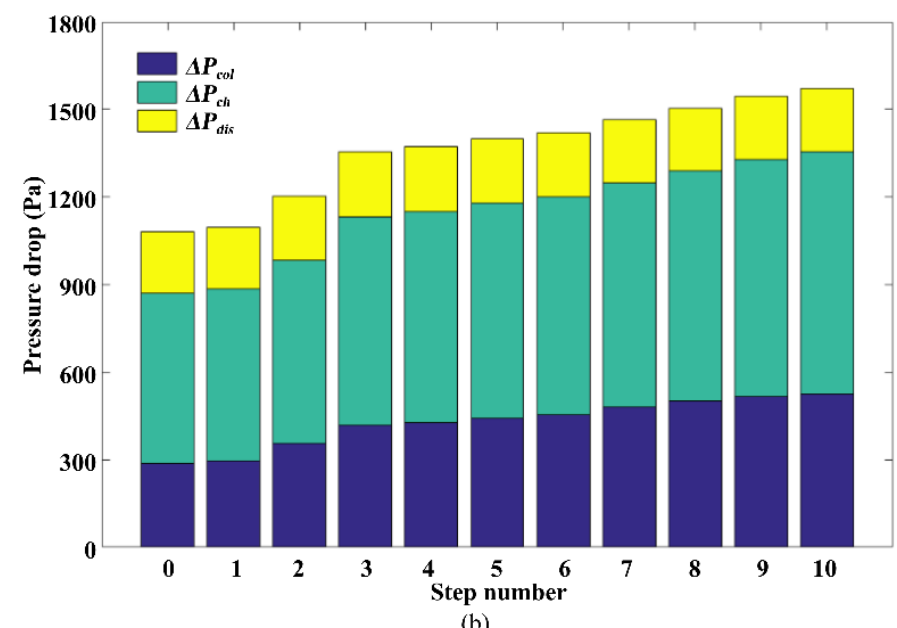

Figure 12. Evolution of the total and sectional pressure drops of the heat sink as a function of optimization step for (a) two-peak heat flux case and (b) five-peak heat flux case 
Fig. 12 shows the evolution of pressure drops of the heat sink versus the optimization step. Different values of pressure drop are plotted, including the total pressure drop $\left(\Delta p_{t o t}\right)$ and sectional pressure drops $\left(\Delta p_{d i s}, \Delta p_{c h}, \Delta p_{c o l}\right)$, for two-peak heat flux case (Fig. 12(a)) and five-peak heat flux case (Fig. 12(b)). For both cases, the total pressure drop as well as the sectional pressure drop increase with the optimization steps, because the adjustment of channel inlet widths for tailoring the flow distribution add supplemental hydraulic resistance. The pressure drop of the parallel mini-channels section $\left(\Delta p_{c h}\right)$ makes the largest contribution to the total pressure drop and continues to grow faster than others $\left(\Delta p_{\text {dis }} ; \Delta p_{\text {col }}\right)$ along with the optimization step. This is because of the changing velocities in channels and the unequal channel inlet widths. The pressure drops in the distributing and collecting manifolds, accounting for a small portion of the total pressure drop, slightly increase with the optimization step for both testing cases.

The pressure drop increase in the parallel channels section is difficult to avoid because of some narrowed channel inlets and tailored non-uniform flow distribution, for the purpose of more efficient cooling. Nevertheless, for the pressure drops in distributing and collecting manifolds, some better header designs [44] may be considered to reduce the total pressure drop. Note that the proposed optimization method is compatible with other manifold shapes.

\section{Effective range of optimized channel inlet widths-a robustness study}

In the above section, it has been demonstrated that under the design heat flux and flow rate conditions, the proposed optimization algorithm is effective in reducing the maximum temperature of the base wall. But for actual use, it will be interesting and of practical significance to further test the optimization method when the workload (heat flux, inlet velocity, etc.) deviates from its design value. The conventional parallel straight channels heat sink with equal channel inlets (step 0) is introduced as a reference for comparison.

\subsection{Effect of inlet velocity}

The optimized heat sink configuration (five-peak heat flux, $V_{\text {in }}=0.6 \mathrm{~m} \cdot \mathrm{s}^{-1}, q_{\text {avg }}=$ $38.75 \mathrm{~W} \cdot \mathrm{cm}^{-2}$ ) was tested under other four inlet velocities (heat flux profile remains unchanged), i.e. $V_{i n}=0.5 \mathrm{~m} \cdot \mathrm{s}^{-1} ; 0.55 \mathrm{~m} \cdot \mathrm{s}^{-1} ; 0.65 \mathrm{~m} \cdot \mathrm{s}^{-1}$ and $0.7 \mathrm{~m} \cdot \mathrm{s}^{-1}$. The thermal resistance $R_{t h}$ (as defined in Eq. (24)) values of the optimized heat sink obtained under different $V_{\text {in }}$ conditions are plotted in the red line in Fig. 13. Note that the blue line shows the $\boldsymbol{R}_{t h}$ value of the heat sink with equal channel inlet widths (step 0 ). In general, the $\boldsymbol{R}_{t h}$ decreases with the increasing mean $R e_{c h}$ for both heat sink configurations because of the higher cooling capacity of the coolant at the higher flow rate. The heat sink with channel inlets optimized under $V_{i n}=0.6 \mathrm{~m} \cdot \mathrm{s}^{-1}\left(\right.$ mean $\left.R e_{c h}=487\right)$, when operated under other inlet velocity (mass flow 
rate) conditions, always shows a lower $R_{t h}$ (about 14\%) than that of the conventional heat sink with equal channel inlet widths.

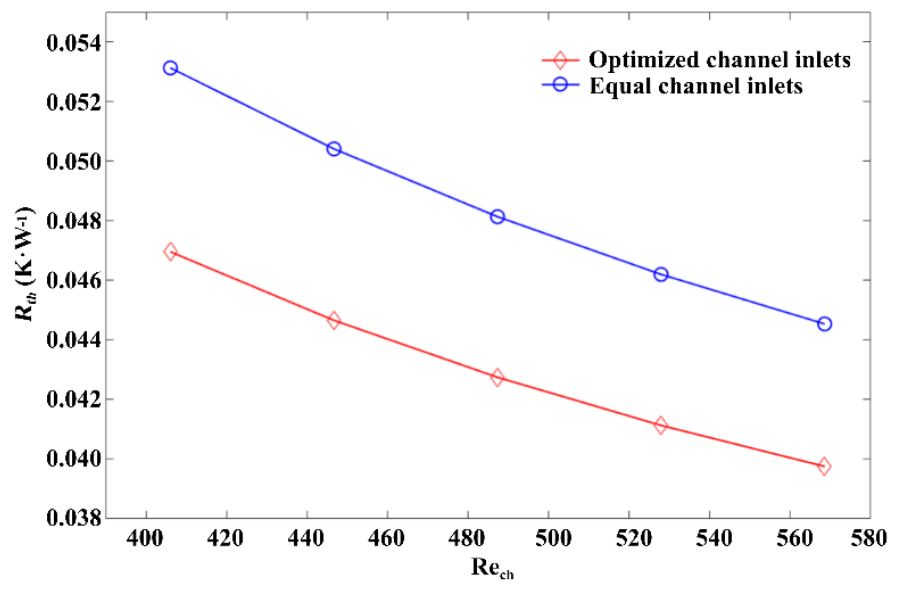

Figure 13. Thermal resistance as a function of mean channel Reynolds number for the optimized heat sink configuration (five-peak heat flux, $V_{i n}=0.6 \mathrm{~m} \cdot \mathrm{s}^{-1}, q_{a v g}=38.75 \mathrm{~W} \cdot \mathrm{cm}^{-2}$ ) and for the conventional heat sink configuration with equal channel inlets

\subsection{Effect of pressure drop increase}

Another option to reduce the thermal resistance and the maximum temperature of the heat sink is simply increasing the mass flow rate (cooling capacity) of the coolant. But similar to any other heat transfer enhancement technique, higher mass flow-rate results in an increased pressure drop (pumping power consumption). It is therefore interesting to compare different cooling enhancement measures considering both the thermal resistance and the pressure drop.

Fig. 14 presents the thermal resistance of the heat sink as a function of the pressure drop, comparing the two cooling enhancements. Note that the blue line shows the performance of the conventional heat sink configuration (equal channel inlet widths) with increasing mass flow rate $\left(V_{i n}=0.6 \mathrm{~m} \cdot \mathrm{s}^{-1}, 0.65 \mathrm{~m} \cdot \mathrm{s}^{-1}, 0.7 \mathrm{~m} \cdot \mathrm{s}^{-1}, 0.75 \mathrm{~m} \cdot \mathrm{s}^{-1}\right)$ whereas the red line represents different optimization steps of the heat sink with varied channel inlet widths $\left(V_{\text {in }}=0.6 \mathrm{~m} \cdot \mathrm{s}^{-1}\right)$. In general, the thermal resistance decreases with the increasing mass flow rate and the pressure drop. An encouraging result is that in order to reach the same thermal resistance, tailoring the flow distribution of the cooling fluid using the proposed optimization method always costs the smaller pressure drop (up to $6.5 \%$ ) than simply increasing the total coolant mass flow rate for conventional parallel straight channels heat sink. The consumed pumping power is better utilized for the cooling purpose to reduce the maximum temperature of the heat sink. 


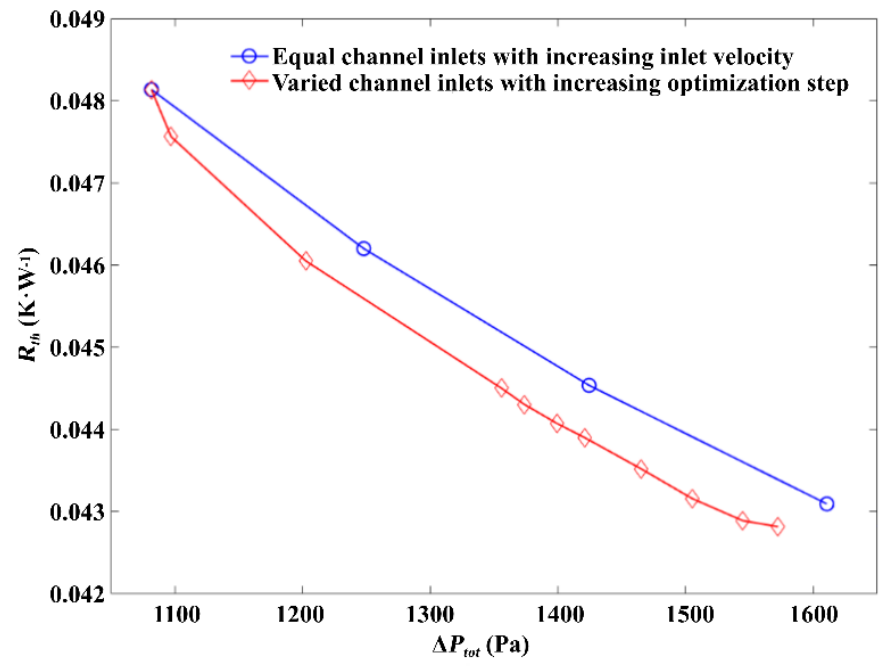

Figure 14. Thermal resistance as a function of total pressure drop of the heat sink by optimizing the channel inlet widths and by increasing the total mass flow rate of cooling fluid

\subsection{Effect of average heat flux}

The power dissipation of electronic devices (e.g. CPU) is often dynamic in actual operation due to the varied frequency and the switched load capacitance. Therefore, testing the optimized heat sink under a certain range of heat flux is necessary. The following test aims to investigate the efficiency and robustness of the optimized heat sink under various average heat fluxes but with a similar pattern since the position of power dissipation elements is often fixed.

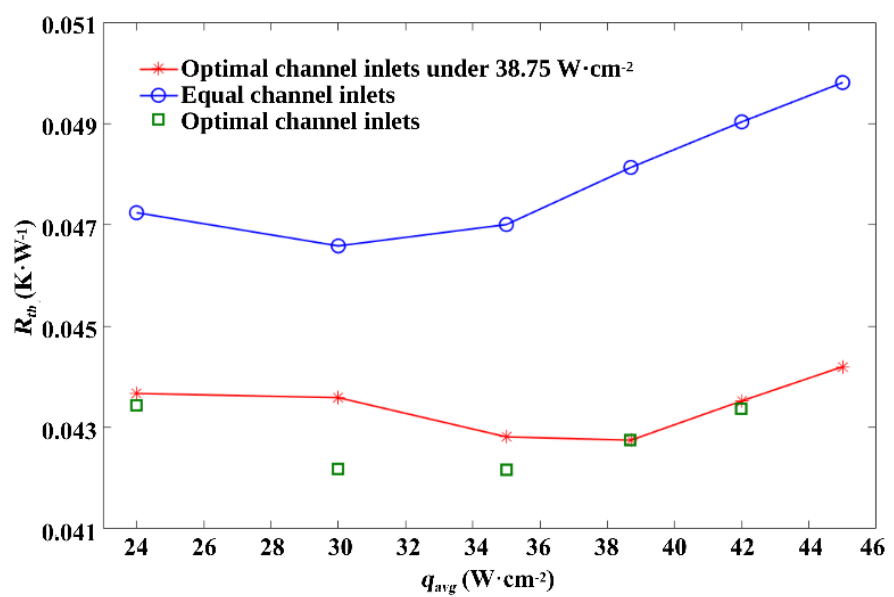

Figure 15. Thermal resistance under different average heat flux conditions for optimized heat sink configuration under $q_{\text {avg }}=38.75 \mathrm{~W} \cdot \mathrm{cm}^{-2}$, for optimized heat sink under corresponding area-weighted average heat flux $\left(q_{a v g}=24-45 \mathrm{~W} \cdot \mathrm{cm}^{-2}\right)$ and for the equal channel inlet widths configuration

Fig. 15 shows the influence of the heat flux variation $\left(q_{\text {avg }}=24-45 \mathrm{~W} \cdot \mathrm{cm}^{-2}\right)$ on the thermal performances of the heat sink. The red line marks the thermal resistance value of 
the optimized heat sink configuration (under five-peak heat flux, $V_{i n}=0.6 \mathrm{~m} \cdot \mathrm{s}^{-1}, q_{a v g}=38.75$ $\left.\mathrm{W} \cdot \mathrm{cm}^{-2}\right)$ while the blue line is for the equal channel inlets configuration. The trend of thermal resistance for both heat sink configurations firstly goes down and then gradually climbs. For equal channel inlets configuration, the lowest thermal resistance is achieved at $q_{\text {avg }}=30 \mathrm{~W} \cdot \mathbf{c m}^{-2}$, while for optimized channel inlets configuration the lowest thermal resistance value is obtained logically under its nominal design condition at $q_{\text {avg }}=38.75$ $\mathrm{W} \cdot \mathrm{cm}^{-2}$. But even not being operated under its nominal design point, the optimized channel inlets configuration can maintain the thermal resistance at a low level, about $9.4 \%$ lower than that of the equal channel inlets configuration. The thermal performance robustness of the optimized channel inlets configuration under variable average heat flux conditions is thereby highlighted.

The green square marker presents the thermal resistance of the heat sink with its channel inlets optimized under the corresponding area-weighted average heat flux. The difference of $R_{t h}$ between nominal design point (green square) and pseudo design point (red star) reduces as the area-weighted average heat flux increases, and the maximum difference of $R_{t h}$ is $0.0014 \mathrm{~K} \cdot \mathrm{W}^{-1}$ at $q_{a v g}=30 \mathrm{~W} \cdot \mathrm{cm}^{-2}$, indicating that the channel inlets optimized under one nominal design heat flux could be considered as pseudo optimal with an acceptable tolerance $(<3 \%)$ when the average heat flux varies within a certain range.

\section{Conclusion and perspectives}

In this paper, a parallel straight mini-channels heat sink subjected to a non-uniform multiple-peak heat flux has been studied, with the purpose of minimizing the maximum temperature on the base wall. The flow distribution of the cooling fluid among the parallel channels is tailored by adjusting the channel inlet widths using an iterative optimization algorithm. The working condition applicability of the optimized channel inlet configuration has also been tested and compared to the equal channel inlet widths heat sink configuration. The main findings obtained may be summarized as follows.

- The maximum temperature can be reduced by $10 \mathrm{~K}$ using the proposed optimization method, under the area-weighted average heat flux of $38.75 \mathrm{~W} \cdot \mathrm{cm}^{-2}$ for the two-peak heat flux case. For the five-peak heat flux case, the maximum temperature can be decreased by $4 \mathrm{~K}$ to $7 \mathrm{~K}$ for the average heat flux ranging from $24-45 \mathrm{~W} \cdot \mathrm{cm}^{-2}$, respectively.

- The heat sink configuration with optimized channel inlets could always provide smaller thermal resistance than that of the equal channel inlet configuration under different average heat flux or total mass flow-rate conditions.

- At the same pressure drop, tailoring the flow distribution of the cooling fluid is more efficient in reducing the thermal resistance than simply increasing the mass flow rate of the cooling liquid. The consumed pumping power is better utilized for the cooling purpose to reduce the maximum temperature of the heat sink. 
- The effectiveness and robustness of the optimization algorithm have been illustrated by that the channel inlet widths configuration optimized under one certain average heat flux could be considered as pseudo optimal with an acceptable tolerance when the average heat flux varies within a certain range.

It should be noted that the proposed optimization method depends largely on the correctness of CFD simulation. The validation of fluid flow and temperature profiles by testing a laboratory heat sink prototype is our ongoing work. In the meantime, developing topology optimization algorithms with more degrees of freedom than the predefined parallel straight channel geometry is also the topic of our current work. Finally, a thermodynamic analysis of the electronic cooling device is expected by proposing some pertinent optimization criteria that accounts for both the heat transfer and the pressure loss performances.

\section{Acknowledgment}

This work is supported by the Chinese Scholarship Council (CSC) with the scholarship for Ms. Yijun LI (No. 201908070033).

\section{Nomenclature}

\section{Latin letters}

$\begin{array}{ll}A & \text { Surface area of the base wall }\left(\mathrm{m}^{2}\right) \\ B & \text { Constant of heat flux formula }\left(\mathrm{W} \cdot \mathrm{cm}^{-2}\right) \\ C p & \text { Specific heat }\left(\mathrm{J} \cdot \mathrm{kg}^{-1} \cdot \mathrm{K}-1\right) \\ D & \text { Hydraulic diameter }(\mathrm{m}) \\ E & \text { Energy }(\mathrm{J}) \\ F & \text { External force }(\mathrm{N}) \\ g & \text { Gravitational acceleration }\left(\mathrm{m} \cdot \mathrm{s}^{-2}\right) \\ h & \text { Specific enthalpy }\left(\mathrm{J} \cdot \mathrm{Kg}^{-1}\right) \\ m & \text { Mass flow rate }\left(\mathrm{kg} \cdot \mathrm{s}^{-1}\right) \\ m^{*} & \text { Non-dimensional mass flow rate }(-) \\ M F_{T^{\max }} & \text { Non-uniformity of maximum temperatures }(-) \\ N & \text { Number of heat peaks }(-) \\ p & \text { Pressure }(\text { Pa }) \\ Q & \text { Heating power }(\mathrm{W}) \\ q & \text { Heat flux }\left(\mathrm{W} \cdot \mathrm{cm}{ }^{-2}\right) \\ R e & \text { Reynolds number }(-) \\ R_{t h} & \text { Thermal resistance }\left(\mathrm{K} \cdot \mathrm{W}{ }^{-1}\right) \\ S_{h} & \text { Volumetric heat source }\left(\mathrm{J} \cdot \mathrm{K}^{-1} \cdot \mathrm{m}^{-3}\right) \\ T & \text { Temperature }(\mathrm{K}) \\ V & \text { Flow velocity }\left(\mathrm{m} \cdot \mathrm{s}^{-1}\right) \\ w & \text { Channel inlet width }(\mathbf{m}) \\ & \end{array}$




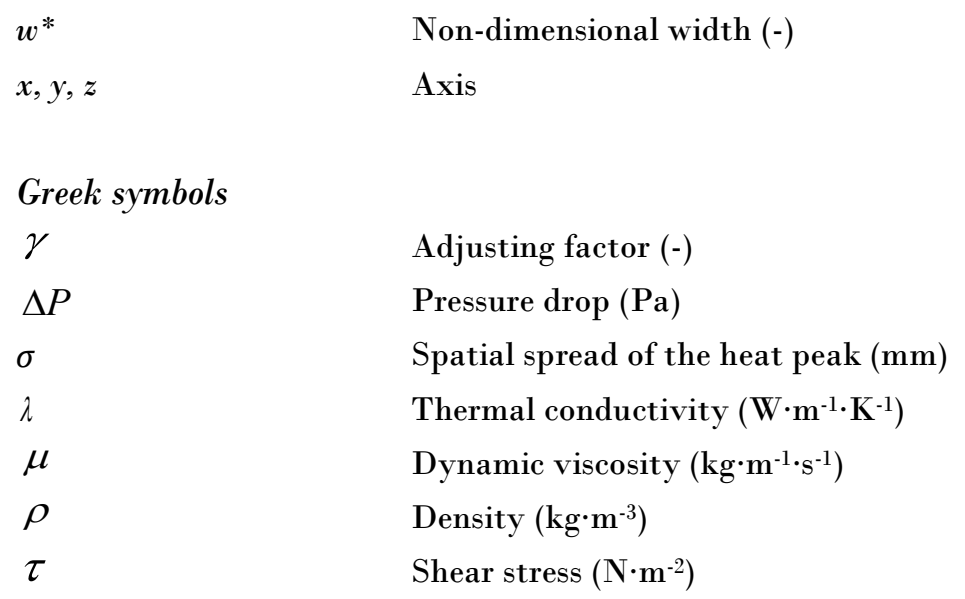

$\begin{array}{ll}\text { avg } & \text { Average value } \\ \text { base } & \text { Heat sink base wall } \\ \text { ch } & \text { Channel } \\ \text { col } & \text { Collector } \\ \text { dis } & \text { Distributor } \\ \text { eff } & \text { Effective } \\ f & \text { Fluid } \\ i & \text { Channel number index } \\ \text { in } & \text { Inlet } \\ k & \text { Iteration step number } \\ \text { max } & \text { Maximum value } \\ \text { min } & \text { Minimum value } \\ \text { out } & \text { Outlet } \\ s & \text { Solid } \\ \text { tot } & \text { Total }\end{array}$

\section{References}

[1] H. Hassan, N.Y.A. Shafey, 3D study of convection-radiation heat transfer of electronic chip inside enclosure cooled by heat sink, Int. J. Therm. Sci. (2021). https://doi.org/10.1016/j.jithermalsci.2020.106585.

[2] W. Puckett, K. Agbim, S. Graham, Cooling of power electronics by integrating sintered Cu particle wick onto a direct-bond copper substrate, in: Proc. 16th Intersoc. Conf. Therm. Thermomechanical Phenom. Electron. Syst. ITherm 2017, 2017. https://doi.org/10.1109//THERM.2017.7992521.

[3] V. Manoj Siva, A. Pattamatta, S.K. Das, Effect of flow maldistribution on the thermal performance of parallel microchannel cooling systems, Int. J. Heat Mass Transf. (2014). https://doi.org/10.1016/j.jijheatmasstransfer.2014.02.017.

[4] Inter, Intel 8 Core ${ }^{\mathrm{TM}}$ i9-10980XE Extreme Edition Processor, Prod. Specif. (n.d.). https://ark.intel.com/content/www/us/en/ark/products/198017/intel-core-i9-10980xe-extreme-editionprocessor-24-75m-cache-3-00-ghz.html (accessed March 4, 2021).

[5] P. Michaud, A Simple Model of Processor Temperature for Deterministic Turbo Clock Frequency, 2019. 
https://hal.archives-ouvertes.fr/hal-02391970.

[6] G. Xia, D. Ma, Y. Zhai, Y. Li, R. Liu, M. Du, Experimental and numerical study of fluid flow and heat transfer characteristics in microchannel heat sink with complex structure, Energy Convers. Manag. (2015). https://doi.org/10.1016/j.enconman.2015.08.042.

[7] J. Wei, Challenges in cooling design of CPU packages for high-performance servers, in: Heat Transf. Eng., 2008. https://doi.org/10.1080/01457630701686727.

[8] M.H. Rashid, Power Electronics Handbook, Elsevier, 2018. https://doi.org/10.1016/C2016-0-00847-1.

[9] G.D. Xia, J. Jiang, J. Wang, Y.L. Zhai, D.D. Ma, Effects of different geometric structures on fluid flow and heat transfer performance in microchannel heat sinks, Int. J. Heat Mass Transf. (2015). https://doi.org/10.1016/j.ijheatmasstransfer.2014.08.095.

[10] S. Kumar, P.K. Singh, Effects of flow inlet angle on flow maldistribution and thermal performance of water cooled mini-channel heat sink, Int. J. Therm. Sci. (2019). https://doi.org/10.1016/j.jithermalsci.2019.01.014.

[11] R. Manikanda Kumaran, G. Kumaraguruparan, T. Sornakumar, Experimental and numerical studies of header design and inlet/outlet configurations on flow mal-distribution in parallel micro-channels, Appl. Therm. Eng. (2013). https://doi.org/10.1016/j.applthermaleng.2013.04.026.

[12] R. Chein, J. Chen, Numerical study of the inlet/outlet arrangement effect on microchannel heat sink performance, Int. J. Therm. Sci. (2009). https://doi.org/10.1016/j.jithermalsci.2008.12.019.

[13] S. Kumar, P.K. Singh, A novel approach to manage temperature non-uniformity in minichannel heat sink by using intentional flow maldistribution, Appl. Therm. Eng. (2019). https://doi.org/10.1016/j.applthermaleng.2019.114403.

[14] H. Liu, P. Li, J. Van Lew, D. Juarez-Robles, Experimental study of the flow distribution uniformity in flow distributors having novel flow channel bifurcation structures, Exp. Therm. Fluid Sci. (2012). https://doi.org/10.1016/j.expthermflusci.2011.10.015.

[15] P. Dabrowski, Mitigation of flow maldistribution in miuichauuel and miuigap heat exchangers by introducing threshold in manifolds, J. Appl. Fluid Mech. (2020). https://doi.org/10.29252/JAFM.13.03.30454.

[16] C. Pistoresi, Y. Fan, L. Luo, Numerical study on the improvement of flow distribution uniformity among parallel mini-channels, Chem. Eng. Process. Process Intensif. 95 (2015). https://doi.org/10.1016/j.cep.2015.05.014.

[17] J. Zhou, M. Ding, H. Bian, Y. Zhang, Z. Sun, Characteristics of flow distribution in central-type compact parallel flow heat exchangers with modified inlet and header, Appl. Therm. Eng. (2020). https://doi.org/10.1016/j.applthermaleng.2019.114636.

[18] I.A. Ghani, N.A. Che Sidik, N. Kamaruzzaman, W. Jazair Yahya, O. Mahian, The effect of manifold zone parameters on hydrothermal performance of micro-channel HeatSink: A review, Int. J. Heat Mass Transf. (2017). https://doi.org/10.1016/j.jiheatmasstransfer.2017.03.007.

[19] J.Y. Song, S. Hah, D. Kim, S.M. Kim, Enhanced flow uniformity in parallel mini-channels with pin-finned inlet header, Appl. Therm. Eng. (2019). https://doi.org/10.1016/j.applthermaleng.2019.02.069.

[20] X. Liu, J. Yu, Numerical study on performances of mini-channel heat sinks with non-uniform inlets, Appl. Therm. Eng. (2016). https://doi.org/10.1016/j.applthermaleng.2015.09.032. 
[21] H.A. Dhahad, E.M. Alfayydh, K.H. Fahim, Effect of flow field design and channel/header ratio on velocity distribution: An experimental approach, Therm. Sci. Eng. Prog. 8 (2018) 118-129. https://doi.org/10.1016/j.tsep.2018.08.013.

[22] Y. Ge, S. Wang, Z. Liu, W. Liu, Optimal shape design of a minichannel heat sink applying multi-objective optimization algorithm and three-dimensional numerical method, Appl. Therm. Eng. (2019). https://doi.org/10.1016/j.applthermaleng.2018.11.038.

[23] Y.T. Mu, L. Chen, Y.L. He, W.Q. Tao, Numerical study on temperature uniformity in a novel mini-channel heat sink with different flow field configurations, Int. J. Heat Mass Transf. (2015). https://doi.org/10.1016/j.jijheatmasstransfer.2015.01.093.

[24] X. Hao, Z. Wu, X. Chen, G. Xie, Numerical analysis and optimization on flow distribution and heat transfer of a U-type parallel channel heat sink, Adv. Mech. Eng. (2015). https://doi.org/10.1155/2014/672451.

[25] I. Mitra, I. Ghosh, Mini-channel heat sink parameter sensitivity based on precise heat flux re-distribution, Therm. Sci. Eng. Prog. 20 (2020) 100717. https://doi.org/10.1016/j.tsep.2020.100717.

[26] Y.J. Kim, Y.K. Joshi, A.G. Fedorov, Y.J. Lee, S.K. Lim, Thermal characterization of interlayer microfluidic cooling of three-dimensional integrated circuits with nonuniform heat flux, J. Heat Transfer. 132 (2010). https://doi.org/10.1115/1.4000885.

[27] R. Mahajan, C.P. Chiu, G. Chrysler, Cooling a microprocessor chip, Proc. IEEE. (2006). https://doi.org/10.1109/JPROC.2006.879800.

[28] L. Sirisha Maganti, P. Dhar, T. Sundararajan, S.K. Das, Selecting Optimal Parallel Microchannel Configuration(s) for Active Hot Spot Mitigation of Multicore Microprocessors in Real Time, J. Heat Transfer. 139 (2017). https://doi.org/10.1115/1.4036643.

[29] B. Ramakrishnan, M. Tradat, Y. Hadad, K. Ghose, B. Sammakia, Characterization of Liquid Cooled Cold Plates for a Multi Chip Module (MCM) and their Impact on Data Center Chiller Operation, in: 2019 IEEE 17th Int. Conf. Ind. Informatics, IEEE, 2019: pp. 1419-1424. https://doi.org/10.1109/INDIN41052.2019.8972030.

[30] O.O. Milman, D.B. Spalding, V.A. Fedorov, Steam condensation in parallel channels with nonuniform heat removal in different zones of heat-exchange surface, Int. J. Heat Mass Transf. (2012). https://doi.org/10.1016/j.jijheatmasstransfer.2012.06.016.

[31] M. Wei, Y. Fan, L. Luo, G. Flamant, Fluid flow distribution optimization for minimizing the peak temperature of a tubular solar receiver, Energy. 91 (2015). https://doi.org/10.1016/j.energy.2015.08.072.

[32] W. Lou, Y. Fan, L. Luo, Single-tank thermal energy storage systems for concentrated solar power: Flow distribution optimization for thermocline evolution management, J. Energy Storage. 32 (2020) 101749. https://doi.org/10.1016/j.est.2020.101749.

[33] J.C.K. Tong, E.M. Sparrow, J.P. Abraham, Attainment of flowrate uniformity in the channels that link a distribution manifold to a collection manifold, J. Fluids Eng. Trans. ASME. (2007). https://doi.org/10.1115/1.2754319.

[34] M. Wei, Y. Fan, L. Luo, G. Flamant, Design and optimization of baffled fluid distributor for realizing target flow distribution in a tubular solar receiver, Energy. (2015). https://doi.org/10.1016/j.energy.2016.04.016.

[35] M. Wei, G. Boutin, Y. Fan, L. Luo, Numerical and experimental investigation on the realization of target flow 
distribution among parallel mini-channels, Chem. Eng. Res. Des. 113 (2016). https://doi.org/10.1016/j.cherd.2016.06.026.

[36] S. Faisal Ahmed, M. Khalid, M. Vaka, R. Walvekar, A. Numan, A. Khaliq Rasheed, N. Mujawar Mubarak, Recent progress in solar water heaters and solar collectors: A comprehensive review, Therm. Sci. Eng. Prog. 25 (2021) 100981. https://doi.org/10.1016/j.tsep.2021.100981.

[37] H.A. Kazem, M.T. Chaichan, A.H.A. Al-Waeli, K. Sopian, Comparison and evaluation of solar photovoltaic thermal system with hybrid collector: An experimental study, Therm. Sci. Eng. Prog. 22 (2021) 100845. https://doi.org/10.1016/j.tsep.2021.100845.

[38] J.E. Hesselgreaves, R. Law, D.A. Reay, Compact heat exchangers: Selection, design and operation: Second Edition, Elsevier, 2016.

[39] L. He, Y. Fan, J. Bellettre, J. Yue, L. Luo, Catalytic methane combustion in plate-type microreactors with different channel configurations: An experimental study, Chem. Eng. Sci. 236 (2021) 116517. https://doi.org/10.1016/j.ces.2021.116517.

[40] Z. Dong, Z. Wen, F. Zhao, S. Kuhn, T. Noël, Scale-up of micro- and milli-reactors: An overview of strategies, design principles and applications, Chem. Eng. Sci. X. 10 (2021) 100097. https://doi.org/10.1016/j.cesx.2021.100097.

[41] B.W. W. M. Kays, M. E. Crawford, Convective Heat and Mass Transfer, 4th Editio, Mcgraw-Hill, 2005.

[42] Engineering ToolBox, Water - Thermal Conductivity, (2018). https://www.engineeringtoolbox.com/waterliquid-gas-thermal-conductivity-temperature-pressure-d_2012.html (accessed March 4, 2021).

[43] Engineering ToolBox, Water - Density, Specific Weight and Thermal Expansion Coefficient, (2003). https://www.engineeringtoolbox.com/water-density-specific-weight-d_595.html (accessed March 4, 2021).

[44] N. Gilmore, A. Hassanzadeh-Barforoushi, V. Timchenko, C. Menictas, Manifold configurations for uniform flow via topology optimisation and flow visualisation, Appl. Therm. Eng. (2021). https://doi.org/10.1016/j.applthermaleng.2020.116227. 